\title{
Country Size, International Trade, and Aggregate Fluctuations in Granular Economies*
}

\author{
Julian di Giovanni \\ International Monetary Fund
}

\author{
Andrei A. Levchenko \\ University of Michigan \\ and NBER
}

October 1, 2012

\begin{abstract}
This paper proposes a new mechanism by which country size and international trade affect macroeconomic volatility. We study a multi-country, multi-sector model with heterogeneous firms that are subject to idiosyncratic firm-specific shocks. When the distribution of firm sizes follows a power law with an exponent close to -1, the idiosyncratic shocks to large firms have an impact on aggregate output volatility. We explore the quantitative properties of the model calibrated to data for the 50 largest economies in the world. Smaller countries have fewer firms, and thus higher volatility. The model performs well in matching this pattern both qualitatively and quantitatively: the rate at which macroeconomic volatility decreases in country size in the model is very close to what is found in the data. Opening to trade increases the importance of large firms to the economy, thus raising macroeconomic volatility. Our simulation exercise shows that the contribution of trade to aggregate fluctuations depends strongly on country size: in the largest economies in the world, such as the U.S. or Japan, international trade increases volatility by only $1.5-3.5 \%$. By contrast, trade increases aggregate volatility by some $15-20 \%$ in a small open economy, such as Denmark or Romania.
\end{abstract}

JEL Classifications: F12, F15, F41

Keywords: Macroeconomic Volatility, Firm-Level Idiosyncratic Shocks, Large Firms, International Trade

\footnotetext{
${ }^{*}$ We are grateful to the editor (Sam Kortum), two anonymous referees, Michael Alexeev, Stijn Claessens, Aaron Flaaen, Fabio Ghironi, Gordon Hanson, Chris House, Marc Melitz, Andy Rose, Matthew Shapiro, Linda Tesar, and workshop participants at various institutions for helpful suggestions, and to Edith Laget, Lin Ma, and Ryan Monarch for expert research assistance. Levchenko thanks the National Science Foundation for financial support under grant SES-0921971. The views expressed in this paper are those of the authors and should not be attributed to the International Monetary Fund, its Executive Board, or its management. E-mail (URL): JdiGiovanni@imf.org (http://julian.digiovanni.ca), alev@umich.edu (http://www.alevchenko.com). The Supplementary Web Appendix to this paper is available at http://alevchenko.com/diGiovanni_Levchenko_granular_web_appendix.pdf.
} 


\section{Introduction}

Output volatility varies substantially across economies: over the past 35 years, the standard deviation of annual real per capita GDP growth has been 2.5 times higher in non-OECD countries compared to the OECD countries. Understanding the sources of these differences is important, as aggregate volatility itself has an impact on a wide variety of economic outcomes. $^{1}$

This paper investigates the role of large firms in explaining cross-country differences in aggregate volatility. We show that the impact of shocks to large firms on aggregate volatility can help account for two robust empirical regularities: (i) smaller countries are more volatile; and (ii) more open countries are more volatile. The key ingredient of our study is that the distribution of firm size is very fat-tailed - the typical economy is dominated by a few very large firms (Axtell, 2001). In a recent contribution, Gabaix (2011) demonstrates that under these conditions idiosyncratic shocks to individual firms do not cancel out and can instead generate aggregate fluctuations (see also Delli Gatti et al., 2005). Gabaix (2011) provides both statistical and anecdotal evidence that even in the largest and most diversified economy in the world - the United States - shocks to the biggest firms can appreciably affect macroeconomic fluctuations. The economy is "granular" rather than smooth.

We develop a theoretical and quantitative framework to study the consequences of this phenomenon in a large cross section of countries. The analysis is based on the canonical multi-country model with heterogeneous firms in the spirit of Melitz (2003) and Eaton et al. (2011), implemented on the 50 largest economies in the world. In order to study the impact of large firms on aggregate fluctuations, the equilibrium total number of firms is determined endogenously in the model, and the parameters are calibrated to match the observed firm size distribution. The solution procedure targets the key aggregate country characteristics - GDPs and average trade volumes - and successfully reproduces a number of non-targeted features of the micro data, such as the share firms that export and the relative size of the largest firms across countries.

Our main results can be summarized as follows. First, the model endogenously generates a negative relationship between country size and aggregate volatility. The reason is that smaller countries will have a smaller equilibrium number of firms (as implied by many models since at least Krugman, 1980), and thus shocks to the largest firms will matter more

\footnotetext{
${ }^{1}$ Numerous studies identify its effects on long-run growth (Ramey and Ramey, 1995), welfare (Pallage and Robe, 2003; Barlevy, 2004), as well as inequality and poverty (Gavin and Hausmann, 1998; Laursen and Mahajan, 2005).
} 
for aggregate volatility. In effect, smaller economies are less diversified, when diversification is measured at the firm level. The model matches this relationship not only qualitatively, but also quantitatively: the rate at which volatility decreases in country size in the model is very similar to what is observed in the data. Both in the model and in the data, a typical country that accounts for $0.5 \%$ of world GDP (such as Poland or South Africa) has aggregate volatility that is 2 times higher than the largest economy in the world - the U.S..

Second, trade openness increases volatility by making the economy more granular. When a country opens to trade, only the largest and most productive firms export, while smaller firms shrink or disappear (Melitz, 2003). This effect implies that after opening, the biggest firms become even larger relative to the size of the economy, thus contributing more to aggregate output fluctuations. In the counterfactual exercise, we compute what aggregate volatility would be for each country in autarky, and compare it to the volatility under the current trade costs. It turns out that at the levels of trade openness observed today, international trade increases volatility relative to autarky in every country. The importance of trade for aggregate volatility varies greatly depending on country characteristics. In the largest economies like Japan or the U.S., aggregate volatility is only 1.5-3.5\% higher than it would have been in complete autarky. In small, remote economies such as South Africa or New Zealand, trade raises volatility by about $10 \%$ compared to autarky. Finally, in small, highly integrated economies such as Denmark or Romania, international trade raises aggregate volatility by some $15-20 \%$.

The theoretical link between country size, trade openness, and volatility we explore in this paper has not previously been proposed. Head (1995) and Crucini (1997) examine the relationship between country size and volatility in a 2-country international real business cycle (IRBC) model. In those papers, the smaller country has higher volatility because the world interest rate is less sensitive to shocks occurring in that country. Thus, following a positive shock it can expand investment without much of an impact on interest rates. ${ }^{2}$ Our explanation for the size-volatility relationship is qualitatively different, and relies instead on the notion that smaller countries have fewer firms. When it comes to the relationship between trade openness and volatility, existing explanations have focused on the propagation

\footnotetext{
${ }^{2}$ The Supplementary Web Appendix implements the canonical IRBC model of Backus et al. (1995), and examines the relationship between country size and volatility, and between trade openness and volatility, in that model. It turns out that while the calibrated IRBC model can produce higher volatility in smaller countries, the relationship between country size and volatility in that model is two orders of magnitude flatter than what is observed in the data. The relationship between trade openness and volatility in the IRBC model is ambiguous, its sign depending crucially on the elasticity of substitution between domestic and foreign goods.
} 
of global demand or supply shocks (Newbery and Stiglitz, 1984; Kraay and Ventura, 2007). We show that trade can increase volatility even if the nature of shocks affecting the firms is unchanged upon opening. Finally, the mechanism in our model resembles the traditional arguments that smaller countries, and more open countries, will have a less diversified sectoral production structure, and thus exhibit higher volatility (see Katzenstein, 1985; OECD, 2006; Blattman et al., 2007, among many others). Our analysis shows that this argument applies to individual firms as well as sectors, and makes this point quantitatively precise by calibrating the model to the observed firm size distribution.

Our work is also related to the empirical literature that studies macroeconomic volatility using disaggregated data. Koren and Tenreyro (2007) explore the importance of sectorspecific shocks in explaining the relationship between a country's level of development and its aggregate volatility, while di Giovanni and Levchenko (2009, 2012b) use sector-level data to study the openness-volatility relationship. Canals et al. (2007) analyze sector- and firmlevel export data and demonstrate that exports are highly undiversified, both across firms and sectors, and across destinations. Furthermore, they show that this feature of export baskets can explain why aggregate macroeconomic variables cannot account for much of the movements in the current account. ${ }^{3}$

The rest of the paper is organized as follows. Section 2 presents the empirical regularities that motivate our study, as well as some novel stylized facts about firm size distributions in a large cross section of countries. Section 3 develops a simple theoretical framework and illustrates analytically the mechanisms behind the key results of the paper. Section 4 presents the quantitative results based on a calibrated model of the world economy. Section 5 discusses robustness checks and results based on model perturbations. Section 6 concludes.

\section{Basic Facts}

Figure 1 presents a scatterplot of log macroeconomic volatility against log country size for a sample of 143 countries. Volatility is the standard deviation of the yearly growth rate of real per capita GDP, while country size is the share of the country in world GDP. ${ }^{4}$ The Figure

\footnotetext{
${ }^{3}$ Our work is complementary to the research agenda that studies the impact of firm dynamics on macroeconomic outcomes in 2-country IRBC models. Ghironi and Melitz (2005) use the heterogeneous firms model to help account for the persistence of deviations from purchasing power parity, while Alessandria and Choi (2007) and Ruhl (2008) evaluate the quantitative importance of firm entry and exit for aggregate trade dynamics. An important difference between these papers and our work is that these contributions examine consequences of aggregate shocks, while in our paper all the shocks are at the firm level. In addition, our work features multiple countries, and explains cross-sectional differences in volatility between countries.

${ }^{4}$ Detailed variable definitions and sources for all the data in this section are described in Appendix A.
} 
depicts the partial correlation between these two variables after netting out per capita income, as it has been shown that high-income countries tend to experience lower volatility. As established by Canning et al. (1998) and Furceri and Karras (2007) among others, smaller countries are more volatile. The elasticity of volatility with respect to country size is about -0.14 in this set of countries, and the relationship is highly significant, with a $t$-statistic of 6.2 .

At the same time, it has been argued that countries that trade more tend to be more volatile. This empirical regularity has been demonstrated in a cross section of countries by Easterly et al. (2001) and Kose et al. (2003). The cross-country evidence is likely to be affected by reverse causality and omitted variables problems. In addition, in a cross-section of countries one does not typically have enough power to distinguish between trade openness and other correlates of macroeconomic volatility (such as, most relevant here, country size). Di Giovanni and Levchenko (2009) investigate the openness-volatility relationship in great detail using industry-level data, which makes it possible to overcome these econometric estimation concerns. They confirm that the relationship between trade openness and macroeconomic volatility is indeed positive and economically significant, even after controlling for the size of both countries and sectors using fixed effects. Below we follow an alternative and complementary strategy to isolate the impact of openness on volatility. We develop a quantitative model that captures a particular channel for this relationship, and evaluate the impact of trade using counterfactual scenarios.

The analysis below focuses on the role of large firms in explaining these cross-country patterns. Anecdotal evidence on the importance of large firms for aggregate fluctuations abounds. Here, we describe two examples in which the roles of country size and international trade are especially evident. In New Zealand a single firm, Fonterra, is responsible for a full one-third of global dairy exports (it is the world's single largest exporter of dairy products). Such a large exporter from such a small country clearly matters for the macroeconomy. Indeed, Fonterra's sales (95\% of which are exports) account for $20 \%$ of New Zealand's overall exports, and $7 \%$ of its GDP. ${ }^{5}$ Two points about this firm are worth noting. First, international trade clearly plays a prominent role in making Fonterra as large as it is. And second, the distribution of firm size in the dairy sector is indeed highly skewed. The second largest producer of dairy products in New Zealand is $1.3 \%$ the size of Fonterra.

\footnotetext{
${ }^{5}$ It is important to note that GDP represents value added, and thus Fonterra's total sales are less than $7 \%$ of the total sales of all firms in New Zealand. However, because exports are recorded as total sales, Fonterra's export sales are directly comparable to New Zealand's total exports. The same caveat applies to the example that follows.
} 
This phenomenon is not confined to commodity exporting countries. In Korea, a larger manufacturing-based economy, the 10 biggest business groups account for 54\% of GDP and $51 \%$ of total exports. Even among the top 10, the distribution of firm size and total exports is extremely skewed. The largest one, Samsung, is responsible for $23 \%$ of exports and $14 \%$ of GDP (see Figure 2). ${ }^{6}$

There is a growing body of additional evidence on the predominance of the largest firms, especially in total exports. Eaton et al. (2012) report that in France the top 10 exporters account for nearly $25 \%$ of total exports. According to Canals et al. (2007), in Japan the top 10 exporters account for about 30\%, and the top 50 exporters for more than half of total exports. Cebeci et al. (2012) report that in a sample of 45 developed and developing countries, the top $1 \%$ of exporters account for $55 \%$ of total exports on average. In a number of countries (Chile, Peru, South Africa) the top $1 \%$ of exporters are responsible for $80 \%$ or so of total exports.

Gabaix (2011) shows that aggregate volatility due to the idiosyncratic shocks to firms is an increasing function of the Herfindahl index of the firms' output shares. To produce the country size-volatility relationship in Figure 1 through the shocks to large firms, it must be the case that smaller countries have higher Herfindahl indices of firm output they are less diversified. Figure 3 a presents the partial correlations between the Herfindahl index of firm sales and country size, after netting out the impact of per capita income, with all variables in natural logs. ${ }^{7}$ The figure also plots the OLS best fit through the data, along with the slope coefficients, standard errors, and the $\mathrm{R}^{2}$ 's. The firm-level data used to compute the Herfindahl indices come from the ORBIS database described in Appendix A. Because the number of firms covered by ORBIS varies substantially across countries, we present the results for three samples: (i) all 134 countries for which it is possible to calculate the Herfindahl index in ORBIS data; (ii) the 81 countries with sales data for at least 100 firms; and (iii) the 52 countries with sales data for at least 1,000 firms. The countries with different numbers of firms are labelled with different symbols. Figure 3a shows that the relationship between the Herfindahl index and country size is negative as expected, and highly statistically significant in all three samples.

The Herfindahl index is the variable most directly relevant to the quantitative results in the paper. However, because ideally it requires information on the entire firm size

\footnotetext{
${ }^{6}$ It turns out that the size distribution of firms is quite skewed even within business groups. For instance, breaking Samsung down into its constituent firms reveals that the sales of Samsung Electronics alone accounted for $7 \%$ of GDP and $15.5 \%$ of Korea's exports in 2006.

${ }^{7}$ The Herfindahl index is defined as the sum of squared shares of firm sales in total sales: $h=\sum_{k} h(k)^{2}$, where $k$ indexes firms, and $h(k)$ is the share of firm $k$ in total sales by all firms.
} 
distribution, the Herfindahl index may also be most heavily influenced by differences in coverage in the ORBIS database. Because of this, we also present the relationship of country size to two other indicators of firm size: the combined sales of the 10 largest firms in the country, and the size of the single largest firm. These indicators focus on the very largest firms that are measured more reliably in the data, and thus the problems of coverage are less severe. In addition, these empirical relationships capture a related feature of the data that is crucial for evaluating the role of large firms for the country size-volatility relationship. A bigger country could either have larger firms, or have more firms, than a smaller country. There are two extreme cases that can be useful benchmarks. The first is that the largest firms in big countries are no bigger than the large firms in small countries. That is, what makes a country larger is that it has more firms, not bigger firms. This hypothetical possibility would manifest itself as a slope of zero in Figures 3b and 3c, and would have important implications for the relationship between country size and (granular) volatility. In particular, a slope of zero would imply that volatility declines very rapidly in country size. The other benchmark is a slope of 1 . When the slope is 1 , the largest firms are no bigger relative to the size of the economy in small countries compared to large ones. That would suggest that larger countries have larger firms but not more firms, and that the size-volatility relationship is perfectly flat: (granular) volatility in the larger countries is no lower than in small countries. ${ }^{8}$ Since these two possibilities have very different implications for how aggregate volatility changes with country size, it is important for our model to match the relative size of the largest firms in countries of different sizes.

Figure $3 \mathrm{~b}$ depicts the partial correlation between the log size of the 10 largest firms and log country size, once again after netting out log per capita income. The results are reported for all three ORBIS samples, as above. There is a significant positive relationship between the absolute size of the largest 10 firms and country size: not surprisingly, larger countries have bigger firms, with an elasticity of around 0.9. The slope coefficient and the fit are both quite stable across the samples. Figure $3 \mathrm{c}$ reports the analogous relationship for the size of the single largest firm in each country, with quite similar conclusions. The fact that the slope is much higher than zero, and indeed only slightly below 1 is suggestive that volatility will decrease with country size, but at a much slower rate than the zero slope benchmark. As we discuss in Section 4.3, our model matches these slope coefficients quite closely.

\footnotetext{
${ }^{8}$ This discussion is of course only suggestive because the precise outcomes will depend on the details of the rest of the firm size distribution, and because we do not have closed-form results with respect to the size of the top 1 or 10 largest firms.
} 


\section{Theoretical Framework}

This section lays out a simplified analytical framework to illustrate the main mechanisms behind the results. The quantitative investigation based on an extended model follows in Section 4. The full description of the equations defining the extended model is presented in Appendix B.

The minimalist framework that can be used to model the role of firms in the relationship between country size and volatility has to feature: (i) a firm size distribution that can be matched to the data; (ii) endogenous determination of the set of firms operating in equilibrium; and (iii) idiosyncratic shocks to firms. In addition, to investigate the role of international trade, the model must have (iv) an export participation decision by firms.

\subsection{The Environment}

Consider a model in the spirit of Melitz (2003), but with a discrete number of goods as in Krugman (1980). The world is comprised of $\mathcal{C}$ countries, indexed by $i, j=1, \ldots, \mathcal{C}$. In country $i$, buyers (who could be final consumers or firms purchasing intermediate inputs) maximize a standard CES objective over the set of $J_{i}$ varieties available in country $i$. It is well known that in country $i$ demand for an individual variety $k$ is equal to

$$
x_{i}(k)=\frac{X_{i}}{P_{i}^{1-\varepsilon}} p_{i}(k)^{1-\varepsilon}
$$

where $\varepsilon$ is the elasticity of substitution between varieties, $x_{i}(k)$ is the total expenditure on good $k$ at price $p_{i}(k), X_{i}$ is total expenditure in the economy, and $P_{i}$ is the ideal price index,

$$
P_{i}=\left[\sum_{k=1}^{J_{i}} p_{i}(k)^{1-\varepsilon}\right]^{\frac{1}{1-\varepsilon}} .
$$

There is one factor of production, labor, with country endowments given by $L_{j}, j=$ $1, \ldots, \mathcal{C}$, and wages denoted by $w_{j}$. Production uses both labor and intermediate inputs. In particular, a firm with unit input requirement $a$ must use $a$ input bundles to produce one unit of output. An input bundle in country $j$ has a cost

$$
c_{j}=w_{j}^{\beta} P_{j}^{1-\beta} .
$$

There are both fixed and variable costs of production and trade. The timing in the economy is depicted in Figure 4. At the beginning of the period each potential producer of variety $k=1, \ldots, \bar{I}_{j}$ in each $j=1, \ldots, \mathcal{C}$ must pay an "exploration" cost $f_{e}$ in order to 
become an entrepreneur. Upon paying this cost, entrepreneur $k$ discovers her productivity, indexed by a unit input requirement $a(k)$, and faces downward-sloping demand for her unique variety given by (1). On the basis of this draw, each entrepreneur in country $j$ decides whether to operate and which markets to serve. To start serving market $i$ from country $j$, a firm must pay a fixed cost $f_{i j}$, and an iceberg per-unit cost of $\tau_{i j}>1$ (with $\tau_{j j}$ normalized to 1). Having paid the fixed costs of entering these markets, the firm learns the realization of a transitory shock $z(k)$, i.i.d. across firms. Once all of the uncertainty has been realized, each firm produces with a unit input requirement $a(k) z(k)$, markets clear, and consumption takes place. ${ }^{9}$

If a firm from country $j$ decides to sell to country $i$, its profit-maximizing price is a constant markup over marginal cost $p_{i}(k)=\frac{\varepsilon}{\varepsilon-1} \tau_{i j} c_{j} a(k) z(k)$, the quantity supplied is equal to $\frac{X_{i}}{P_{i}^{1-\varepsilon}}\left(\frac{\varepsilon}{\varepsilon-1} \tau_{i j} c_{j} a(k) z(k)\right)^{-\varepsilon}$, and its expected profits from serving $i$ are

$$
\mathrm{E}\left[\frac{X_{i}}{\varepsilon P_{i}^{1-\varepsilon}}\left(\frac{\varepsilon}{\varepsilon-1} \tau_{i j} c_{j} a(k) z(k)\right)^{1-\varepsilon}-c_{j} f_{i j} \mid a(k)\right] .
$$

Because of fixed costs of serving a market, there is a cutoff unit input requirement $a_{i j}$ above which firms in country $j$ do not serve market $i$, defined as the level of $a(k)=a_{i j}$ such that the expected profits in equation (3) equal zero. To go forward with the analysis, we make the following two assumptions:

Assumption 1 The marginal firm is small enough that it ignores the impact of its own realization of $z(k)$ on the total expenditure $X_{i}$ and the price level $P_{i}$ in all potential destination markets $i=1, \ldots, \mathcal{C}$.

Assumption 2 The marginal firm treats $X_{i}$ and $P_{i}$ as fixed (non-stochastic).

The first assumption is not controversial, and has been made in the literature since Dixit and Stiglitz (1977) and Krugman (1980). The second assumption allows us to take $X_{i}$ and $P_{i}$ outside of the expectation operator. It amounts to assuming that the marginal

\footnotetext{
${ }^{9}$ Note that the assumption on the timing of events, namely that the decision to enter markets takes place before $z(k)$ is realized, implies that the realization of the firm-specific transitory shock does not affect the equilibrium number of firms in each market. This simplification lets us analyze the equilibrium production allocation as an approximation around a case in which the variance of $z$ is zero. That is, we abstract from the extensive margin of exports, and entry and exit of firms in response to transitory shocks. This simplification delivers substantial analytical convenience, while it is unlikely to affect the results. This is because the focus of the paper is on the role of the largest firms in generating aggregate volatility, and the largest firms are inframarginal: their entry decision will be unaffected by the realization of the transitory shock. Note also that this timing assumption implies that our analytical approach is akin to the common one of analyzing the response to shocks in deviations from a non-stochastic steady state.
} 
entrepreneur ignores the volatility of aggregate output and the price level when deciding to enter a market. ${ }^{10}$ Under these two assumptions, setting (3) to zero and taking the expectation over $z$, the zero profit cutoff condition for serving market $i$ from country $j$ reduces to

$$
a_{i j}=\frac{\varepsilon-1}{\varepsilon} \frac{P_{i}}{\tau_{i j} c_{j}}\left(\frac{X_{i}}{\varepsilon c_{j} f_{i j}}\right)^{\frac{1}{\varepsilon-1}}
$$

after normalizing the transitory shocks $z$ such that $\mathrm{E}_{z}\left(z^{1-\varepsilon}\right)=1$.

The equilibrium number of potential entrepreneurs $\bar{I}_{j}$ is pinned down by the familiar free entry condition in each country. Entrepreneurs will enter until the expected profit equals the cost of finding out one's type:

$$
\mathrm{E}\left[\sum_{i=1}^{\mathcal{C}} \mathbf{1}\left[a(k) \leq a_{i j}\right]\left(\frac{X_{i}}{\varepsilon P_{i}^{1-\varepsilon}}\left(\frac{\varepsilon}{\varepsilon-1} \tau_{i j} c_{j} a(k) z(k)\right)^{1-\varepsilon}-c_{j} f_{i j}\right)\right]=c_{j} f_{e},
$$

for each country $j$, where $\mathbf{1}[\cdot]$ is the indicator function.

Closing the model involves finding expressions for $a_{i j}, P_{i}, w_{i}$, and $\bar{I}_{i}$ for all $i, j=1, \ldots, \mathcal{C}$. As an approximation, we solve for the equilibrium production allocation and price levels ignoring firm-specific transitory shocks. Taking the expectations over $a(k)$ and $z(k)$, and using the fact that $\mathrm{E}_{z}\left(z^{1-\varepsilon}\right)=1$, the price levels become ${ }^{11}$

$$
P_{i}=\left[\sum_{j=1}^{\mathcal{C}}\left(\frac{\varepsilon}{\varepsilon-1} \tau_{i j} c_{j}\right)^{1-\varepsilon} \bar{I}_{j} \operatorname{Pr}\left(a<a_{i j}\right) \mathrm{E}\left(a^{1-\varepsilon} \mid a<a_{i j}\right)\right]^{\frac{1}{1-\varepsilon}}
$$

We make the standard distributional assumption on productivity:

\footnotetext{
${ }^{10}$ It is important to emphasize that these are assumptions placed on the behavior of the marginal entrepreneur. They allow us to compute the cutoffs for production and exporting $a_{i j}$ as if the model was non-stochastic. This delivers substantial analytical and computational simplicity without affecting any of the main conclusions, since in our model the economy is dominated by very large firms, and thus the marginal ones are not important for the aggregate outcomes. On the other hand, one may question our assumption about the behavior of the largest firms, namely that markups are a constant multiple of marginal cost. If the largest firms in the economy are so large that their pricing decisions can affect the price level, their profit-maximizing prices will depart from the simple Dixit-Stiglitz constant markup benchmark. Note that qualitatively, this critique applies to all implementations of the Dixit-Stiglitz framework, and their extensions to heterogeneous firms. It is ultimately a quantitative question how much this force matters (Yang and Heijdra, 1993; Dixit and Stiglitz, 1993). While the full solution of our model under flexible markups would be impractical, and to our knowledge has not yet been implemented in this type of large-scale setting, we can perform a simple simulation that assesses the quantitative importance of allowing for variable markups in this setting. The Supplementary Web Appendix describes the exercise in detail, and shows that quantitatively, the deviations of flexible-markup prices from the constant-markup benchmark are very small even for the largest firms in small countries.

${ }^{11}$ Comparing the expressions for the price levels in (2) and (6), the set of varieties $J_{i}$ available in country $i$ is comprised of varieties coming from all countries serving market $i$. Thus, the expected number of varieties available in country $i$ is equal to $\sum_{j=1}^{\mathcal{C}} \bar{I}_{j} \operatorname{Pr}\left(a<a_{i j}\right)$.
} 
Assumption 3 Firm productivity $1 /$ a follows a Pareto $(b, \theta)$ distribution: $\operatorname{Pr}(1 / a<y)=$ $1-(b / y)^{\theta}$, where $b$ is the minimum value productivity can take, and $\theta$ regulates dispersion.

Using the distributional assumption to compute the cdf's and conditional expectations over $a$, and plugging in the expressions for $a_{i j}$ in (4), the price levels become

$$
P_{i}=\frac{1}{b}\left[\frac{\theta}{\theta-(\varepsilon-1)}\right]^{-\frac{1}{\theta}} \frac{\varepsilon}{\varepsilon-1}\left(\frac{X_{i}}{\varepsilon}\right)^{-\frac{\theta-(\varepsilon-1)}{\theta(\varepsilon-1)}}\left(\sum_{j=1}^{\mathcal{C}} \bar{I}_{j}\left(\frac{1}{\tau_{i j} c_{j}}\right)^{\theta}\left(\frac{1}{c_{j} f_{i j}}\right)^{\frac{\theta-(\varepsilon-1)}{\varepsilon-1}}\right)^{-\frac{1}{\theta}}
$$

The model is closed by assuming balanced trade in each country, which delivers a system of equations defining the vector of equilibrium wages $w_{i}$. The definition of equilibrium and the set of equilibrium conditions for the complete 2-sector model are laid out in Appendix B. In the remainder of this section, we use the relationships implied by the simple model above to illustrate the main mechanisms behind our results.

\subsection{Power Law in Firm Size and Aggregate Volatility in the Model and the Data}

Total sales in the economy is defined by

$$
X=\sum_{k=1}^{I} x(a(k), z(k))
$$

where $I$ is the total number of operating firms, $x(a(k), z(k))$ is the sales of firm $k$, and we omit the country subscripts. Appendix $\mathrm{C}$ shows that the standard deviation of the growth rate of aggregate sales, or more precisely of the deviation from the expected aggregate sales, is equal to

$$
\operatorname{Std}_{z}\left(\frac{\Delta X}{\mathrm{E}_{z}(X)}\right)=\sigma \sqrt{h}
$$

where $h=\sum_{k=1}^{I} h(k)^{2}$ is the Herfindahl index of production shares of firms in this economy, and $\sigma$ is the standard deviation of the growth rate of sales of an individual firm. This is the familiar expression for the standard deviation of a weighted sum of random variables, and is the same as the one used by Gabaix (2011). ${ }^{12}$

This economy is granular, that is, idiosyncratic shocks to firms result in aggregate fluctuations, if the distribution of firm size follows a power law with an exponent sufficiently close to 1 in absolute value. In other words, firm sales $x$ in the economy must conform to

$$
\operatorname{Pr}(x>q)=\delta q^{-\zeta}
$$

\footnotetext{
${ }^{12}$ Note that there are no aggregate shocks in the model, only the firm-specific idiosyncratic shocks.
} 
where $\zeta$ is close to 1. Gabaix (2011, Proposition 2) shows that when the firm size distribution follows a power law with an exponent $-\zeta$, the economy is populated by $\mathcal{N}$ firms, and each firm has a standard deviation of sales growth equal to $\sigma$, the aggregate volatility given by (9) is proportional to $\sigma / \mathcal{N}^{1-1 / \zeta}$ for $1<\zeta<2$, and to $\sigma / \log \mathcal{N}$ when $\zeta=1$. This result means that when $\zeta<2$ and thus the distribution of firm size has infinite variance, the conventional Law of Large Numbers does not apply, and aggregate volatility decays in the number of firms $\mathcal{N}$ only very slowly. In other words, under finite variance in the firm size distribution, aggregate volatility decays at rate $\sqrt{\mathcal{N}}$ in the number of firms. But under Zipf's Law - defined as $\zeta \approx 1$ - it decays only at rate $\log \mathcal{N}$.

In this paper, we take this statistical result for granted. This section relates it to our theoretical framework by first demonstrating how the parameters of the model can be calibrated to the observed distribution of firm size. Then, we discuss the two key comparative statics: the role of country size and the role of trade openness in aggregate volatility.

It turns out that the baseline Melitz-Pareto model delivers a power law in firm size. We demonstrate the power law in an autarkic economy, and then discuss how the distribution of firm size is affected by international trade. In our model, the expected sales of a firm as a function of its unit input requirement are: $x(a)=D a^{1-\varepsilon}$, where the constant $D$ reflects the size of domestic demand. Under the assumption that $1 / a \sim \operatorname{Pareto}(b, \theta)$, the power law follows:

$$
\operatorname{Pr}(x>q)=\operatorname{Pr}\left(D a^{1-\varepsilon}>q\right)=\operatorname{Pr}\left(\frac{1}{a}>\left(\frac{q}{D}\right)^{\frac{1}{\varepsilon-1}}\right)=\left(\frac{b^{\varepsilon-1} D}{q}\right)^{\frac{\theta}{\varepsilon-1}}
$$

satisfying (10) for $\delta=\left(b^{\varepsilon-1} D\right)^{\frac{\theta}{\varepsilon-1}}$ and $\zeta=\frac{\theta}{\varepsilon-1}$. This relationship is depicted in Figure 5 . Thus, our model economy will be granular if $\frac{\theta}{\varepsilon-1}$ is close enough to 1 - the power law exponent in the data (see, among others, Axtell, 2001; di Giovanni and Levchenko, 2012a; di Giovanni et al., 2011).

Gabaix (2011) shows that although aggregate volatility decays in the number of firms much more slowly than under the conventional LLN, countries with a greater number of firms $\mathcal{N}$ will nonetheless have lower aggregate volatility. This forms the basis of the relationship between country size and aggregate volatility. Larger countries - those with higher $L$ in our model - will feature a larger number of firms in equilibrium. Thus, they can be expected to have lower aggregate volatility. This can be demonstrated most transparently in the autarky equilibrium. Setting the number of countries $\mathcal{C}=1$ and using the Pareto distributional assumption, equation (5) can be used to compute the production cutoff $a_{a u t}$ consistent with free entry. With zero net aggregate profits, the total expenditure in the 
economy is equal to $X=L / \beta$, where we set the wage to be the numéraire. Equations (4) and $(7)$ then imply that the equilibrium number of entrants $\bar{I}_{\text {aut }}$ is proportional to:

$$
\bar{I}_{\text {aut }} \sim L^{\frac{1}{1-\frac{1-\beta}{\beta} \frac{1}{\varepsilon-1}}}
$$

This is the well-known result that the number of firms increases in country size, measured by $L$. It is immediate that without input-output linkages $(\beta=1)$, the relationship is simply proportional. ${ }^{13}$ The presence of input-output linkages actually tends to raise this elasticity above 1: as long as $\beta \varepsilon>1$, the number of firms responds more than proportionately to the increase in market size. The condition that $\beta \varepsilon>1$ is akin to the "no black hole" assumption (Fujita et al., 2001). Otherwise, if $\beta \varepsilon<1$ increasing returns are so strong that countries with higher $L$ actually have a smaller number of entrants. ${ }^{14}$ We impose the restriction that $\beta \varepsilon>1$ throughout. It is likely to be comfortably satisfied in the data, as available estimates put $\beta$ in the range of 0.5 , while $\varepsilon$ is typically assumed to be around 6 (see Section 4.1 for details). ${ }^{15}$ The equilibrium relationship (11) combined with Zipf's Law in firm size thus forms the basis for the first main result of the paper: smaller countries will have fewer firms, and thus higher aggregate volatility.

\subsection{International Trade and Aggregate Volatility}

How does international trade affect the distribution of firm size and therefore aggregate volatility? As first demonstrated by Melitz (2003), the distribution of firm size becomes more unequal under trade: compared to autarky, the least productive firms exit, and only the most productive firms export abroad. Due to competition from foreign varieties, domestic sales and profits decrease. Thus, as a country opens to trade, sales of most firms shrink, while the largest firms grow larger as a result of exporting. ${ }^{16}$ Figure 5 depicts this effect.

\footnotetext{
${ }^{13}$ In that case, the solution for the equilibrium number of entrants has the particularly simple form: $\bar{I}_{a u t}=\frac{L}{\varepsilon f_{e}} \frac{\varepsilon-1}{\theta}$.

${ }^{14}$ The model does not have a solution when $\beta \varepsilon=1$, and the equilibrium $\bar{I}_{a u t}$ is discontinuous in $\beta \varepsilon$ in the neighborhood of $\beta \varepsilon=1$ : as $\beta \varepsilon \rightarrow 1$ from below $\bar{I}_{\text {aut }}$ goes to zero, but as $\beta \varepsilon \rightarrow 1$ from above $\bar{I}_{\text {aut }}$ goes to infinity.

${ }^{15}$ One may wonder whether the larger number of entrants $\bar{I}$ actually translates into a larger number of operating firms, since not all entrants decide to produce. The number of operating firms is given by $\bar{I}_{a u t} G\left(a_{a u t}\right)$, where $G(\cdot)$ is the cdf of $a$. The solution to $a_{a u t}$ does not depend on $L$ in this model, and thus the number of actual operating firms is proportional to $\bar{I}_{\text {aut }}$.

${ }^{16}$ Firm-level studies of dynamic adjustment to trade liberalization appear to find empirical support for these predictions. Pavcnik (2002) provides evidence that trade liberalization led to a shift in resources from the least to the most productive firms in Chile. Bernard et al. (2003) show that a fall in trade costs leads to both exit by the least productive firms and entry by firms into export markets. In addition, existing exporters ship more abroad. A recent contribution by Holmes and Stevens (2010) shows that in the U.S., in some sectors the large firms are the ones suffering the most from foreign competition, because smaller
} 
In the two-country case, there is a single productivity cutoff, above which firms export abroad. Compared to autarky, there is a higher probability of finding larger firms above this cutoff. In the $\mathcal{C}$-country case with multiple export markets, there will be cutoffs for each market, with progressively more productive firms exporting to more and more markets and growing larger and larger relative to domestic GDP. Thus, if the distribution of firm sales follows a power law and the economy is granular, international trade has the potential to increase the size of the largest firms, in effect creating a "hyper-granular" economy, with clear implications for the relationship between trade openness and aggregate volatility. All else equal, this "selection into exporting" effect implies that after trade opening, aggregate volatility increases.

Before moving on to the quantitative assessment of the relationships between country size, international trade, and volatility illustrated above, we allude to another mechanism through which trade can affect volatility in a model with free entry. When a country opens to trade, the possibility of getting a sufficiently high productivity draw and becoming an exporter induces more potential entrepreneurs to enter and draw their productivity: $\bar{I}$ rises. Because aggregate volatility decreases in the number of firms, this "net entry" effect will tend to decrease volatility when a country opens to trade. As Section 5 demonstrates, however, this effect is quite small quantitatively: the impact of international trade on aggregate volatility is virtually the same whether we allow new net entry after opening or

firms are highly specialized boutique operations that are less affected by imports than the large factories producing standardized products with close foreign substitutes. The point made by Holmes and Stevens (2010) is a very important one, but it can be thought of as one about industrial classification: large factories and boutique ones produce different types of goods, which face very different market structures - competitive environments, trade costs, and so on. This comes through most clearly in the modeling approach adopted in that paper, in which it classifies the small boutique producers as nontradeable. Thus, the Holmes and Stevens (2010) finding can be easily reconciled with our complete two-sector model, described in Appendix B and used in the quantitative analysis, by assuming that the standardized producers are part of the tradeable sector, while the boutique producers are part of the non-tradeable sector. Indeed, this is very close to the assumption that Holmes and Stevens (2010) actually adopt in their model. 
not. $^{17}$

\section{Quantitative Assessment}

Though the analytical results obtained in a one-sector model are informative, we would like to evaluate quantitatively the importance of these mechanisms and exploit the rich heterogeneity among the countries in the world. In order to do this, we numerically implement a multi-country model that extends the framework in Section 3 to include a non-traded sector with intermediate input linkages both within and between sectors. Since only the minority of economic activity takes place in sectors with substantial cross-border trade, including an explicitly non-traded sector in the quantitative exercise is especially important for evaluating the impact of international trade on volatility.

In particular, suppose that in each country there are two broad sectors, the tradeable $T$ and the non-tradeable $N$. Consumer preferences are Cobb-Douglas in CES aggregates of $N$ and $T$, with the share of $N$ in final expenditure equal to $\alpha$. Intermediate inputs are also Cobb-Douglas in the $N$ and $T$ aggregates, with the share of $N$ equal to $\eta_{s}$ in sector $s=N, T$. The share of labor in total spending on inputs, $\beta_{s}$, will also now vary by sector. The rest of the model remains unchanged. Appendix B presents the complete description of the equations defining the equilibrium in the two-sector model.

\footnotetext{
${ }^{17}$ We can use a back of the envelope calculation to illustrate why quantitatively free entry plays such a minor role for the impact of trade. When countries are symmetric $\left(L_{i}=L, f_{i i}=f \forall i\right.$, and $\tau_{i j}=\tau, f_{i j}=f^{X}$ $\forall i, j)$, the number of entrants under trade is

$$
\bar{I}_{\text {trade }}=\left[1+(\mathcal{C}-1) \tau^{-\theta}\left(f / f^{X}\right)^{\frac{\theta-(\varepsilon-1)}{\varepsilon-1}}\right]^{\frac{1-\beta}{\beta \theta} \frac{1}{1-\frac{1-\beta}{\beta} \frac{1}{\varepsilon-1}}} \bar{I}_{\text {aut }} .
$$

Trade opening thus increases the number of entrants relative to autarky under the maintained assumption that $\beta \varepsilon>1$, since the term in the square brackets is larger than 1. At reasonable parameter values, the exponent on the the square bracket in equation (12) is quite small, and thus the change in $\bar{I}$ from autarky to trade is modest. Furthermore, even if the number of operating firms increases by as much as the difference between $\bar{I}_{a u t}$ and $\bar{I}_{\text {trade }}$, this effect alone would amount to a proportional reduction in volatility of only $1-\left(\bar{I}_{\text {trade }} / \bar{I}_{\text {aut }}\right)^{1-1 / \zeta}$, which is very small if $\zeta$ is close to 1 . To get a sense of the magnitudes, we plug in the parameter values for $\tau, f, f_{X}, \theta, \varepsilon$, and $\beta$ from the quantitative model below (see Section 4.1 and Table 1). It turns out that with 100 symmetric countries (each thus accounting for $1 \%$ of world GDP), $\bar{I}_{\text {trade }} / \bar{I}_{\text {aut }}=1.21$, which alone would imply a reduction in aggregate volatility of only $0.9 \%$ compared to autarky. With 200 countries (each $0.5 \%$ of world GDP), the reduction is $1.4 \%$. These are upper bounds, because the number of actual operating firms will increase by less than the term in brackets in (12), as the production cutoffs will also become more stringent under trade.
} 


\subsection{Calibration}

We numerically implement the economy under the following parameter values (see Table 1 for a summary). The elasticity of substitution is $\varepsilon_{s}=6$. Anderson and van Wincoop (2004) report available estimates of this elasticity to be in the range of 3 to 10 , and we pick a value close to the middle of the range. The key parameter is $\theta_{s}$, as it governs the slope of the power law. As described above, in this model firm sales follow a power law with the exponent equal to $\frac{\theta_{s}}{\varepsilon_{s}-1}$. In the data, firm sales follow a power law with the exponent close to 1. Axtell (2001) reports the value of 1.06, which we use to find $\theta_{s}$ given our preferred value of $\varepsilon_{s}: \theta_{s}=1.06 \times\left(\varepsilon_{s}-1\right)=5.3$. We set both the elasticity of substitution and the Pareto exponent to be the same in the $N$ and the $T$ sectors. Appendix Section B.1 justifies in detail the calibration of the two-sector model parameters to the observed firm size distributions.

We set the share of non-tradeables in consumption $\alpha=0.65$. This is the mean value of services value added in total value added in the database compiled by the Groningen Growth and Development Center and extended to additional countries by Yi and Zhang (2010). It is the value also adopted by Alvarez and Lucas (2007). The values of $\beta_{N}$ and $\beta_{T}-$ share of labor/value added in total output - are calibrated using the 1997 U.S. Benchmark Input-Output Table. We take the Detailed Make and Use tables, featuring more than 400 distinct sectors, and aggregate them into a 2-sector Direct Requirements Table. This table gives the amount of $N, T$, and factor inputs required to produce a unit of final output. Thus, $\beta_{s}$ is equal to the share of total sector $s$ output that is not used to pay for intermediate inputs, i.e., the payments to factors of production. According to the U.S. Input-Output Matrix, $\beta_{N}=0.65$ and $\beta_{T}=0.35$ : the traded sector is considerably more input-intensive than the non-traded sector. The shares of non-traded and traded inputs in both sectors are also calibrated based on the U.S. I-O Table. According to the data, more than $75 \%$ of the inputs used in the $N$ sector come from the $N$ sector itself $\left(\eta_{N}=0.77\right)$, while only $35 \%$ of $T$-sector inputs are non-tradeable $\left(\eta_{T}=0.35\right)$. Nonetheless, these values still leave substantial room for cross-sectoral input-output linkages.

To calibrate the values of $\tau_{i j}$ for each pair of countries we use the gravity estimates from the empirical model of Helpman et al. (2008). To take a stand on the values of $f_{i i}^{s}$ and $f_{i j}^{s}$, we follow di Giovanni and Levchenko (2012a) and use the information on entry costs from the Doing Business Indicators database (The World Bank, 2007a). The data sources and the details of the calibration of $\tau_{i j}$ and $f_{i j}^{s}$ are described in Appendix A.

Finally, we set the value of the "exploration cost" $f_{e}$ such that the equilibrium number 
of operating firms in the U.S. is equal to 7 million. According to the 2002 U.S. Economic Census, there were 6,773,632 establishments with a payroll in the United States. There are an additional 17,646,062 business entities that are not employers, but they account for less than $3.5 \%$ of total shipments. Thus, while the U.S. may have many more legal entities than what we assume here, 7 million is a number sufficiently high as to let us consider consequences of granularity. Since we do not have information on the total number of firms in other countries, we choose to set $f_{e}$ to be the same in all countries. In the absence of data, this is the most agnostic approach we could take. In addition, since $f_{e}$ represents the cost of finding out one's abilities, we do not expect it to be affected by policies and thus differ across countries. The resulting value of $f_{e}$ is 15 times higher than $f_{U S, U S}^{s}$, and 2.4 times higher than the average $f_{i i}^{s}$ in the rest of the sample. The finding that the ex-ante fixed cost of learning one's type is much higher than the ex-post fixed cost of production is common in the quantitative models of this type (see, e.g., Ghironi and Melitz, 2005).

We carry out the analysis on the sample of the largest 49 countries by total GDP, plus the 50th that represents the rest of the world. These 49 countries together cover $97 \%$ of world GDP. We exclude the entrepôt economies of Hong Kong and Singapore, both of which have total trade well in excess of their GDP due to significant re-exporting activity. Thus, our model is not intended to fit these countries. (We do place them into the rest-of-the-world category.) The country sample, sorted by total GDP, is reported in Table 2.

\subsection{Model Solution and Simulation Method}

In order to solve the model numerically, we must find the wages and price indices for each country, $w_{i}, P_{i}^{N}, P_{i}^{T}$, that satisfy equations (B.1), (B.2), and (B.3), jointly with the values of $\bar{I}_{i}^{N}$ and $\bar{I}_{i}^{T}$ that satisfy equations (5) for each sector. The system is non-reducible, such that all of the prices and numbers of entrants must be solved simultaneously. Note that in this step the equilibrium values are computed under the assumption that the model aggregates take on their expected values. That is, this step ignores any variation in $P_{i}^{s}$ 's,

$\bar{I}_{i}^{s}$ 's, and $a_{i j}^{s}$ 's that would arise from one random draw of a vector of $a$ 's to another - a common approach in monopolistic competition models.

Using the equilibrium equations and the chosen parameter values, we can solve the full model for a given vector of $L_{i}$. For finding the values of $L_{i}$, we follow the approach of Alvarez and Lucas (2007). First, we would like to think of $L_{i}$ not as population per se, but as "equipped labor," to take explicit account of TFP and capital endowment differences between countries. To obtain the values of $L_{i}$ that are internally consistent in the model, 
we start with an initial guess for $L_{i}$ for all $i=1, \ldots, \mathcal{C}$, and use it to solve the full model. Given the solution for wages, we update our guess for $L_{i}$ for each country in order to match the GDP ratio between each country $i$ and the U.S.. Using the resulting values of $L_{i}$, we solve the model again to obtain the new set of wages, and iterate to convergence (for more on this approach, see Alvarez and Lucas, 2007). Thus, our procedure generates vectors $w_{i}$ and $L_{i}$ in such a way as to match exactly the relative total GDPs of the countries in the sample. In practice, the results are close to simply equating $L_{i}$ to the relative GDPs. In this procedure, we must normalize the population of one of the countries. We thus set $L_{U S}$ to its actual value of 291 million as of 2003, and compute $L_{i}$ of every other country relative to this U.S. value. An important consequence of this approach is that countries with higher TFP and capital abundance will tend to have a greater number of potential productivity draws $\bar{I}_{i}^{s}$, all else equal, since our procedure will effectively give them a higher $L_{i}$. This is akin to the assumption adopted by Alvarez and Lucas (2007) and Chaney (2008) that the number of productivity draws is a constant multiple of equipped labor $L_{i}$. The difference in our approach is that though we take labor-cum-productivity to be the measure of market size, we solve for $\bar{I}_{i}^{N}$ and $\bar{I}_{i}^{T}$ endogenously within the model.

Having solved the model given the data on country GDPs and trade costs, we now simulate it using random productivity draws for each firm in each economy. Namely, in each country $i$ and sector $s$ we draw $\bar{I}_{i}^{s}$ productivities from a $\operatorname{Pareto}\left(b_{s}, \theta_{s}\right)$ distribution. For each firm, we use the cutoffs $a_{j i}^{s}$ for serving each market $j$ (including its own market $j=i$ ) given by equation (4) to determine whether the firm operates, and which, if any, foreign markets it serves. We next calculate the total sales of each firm as the sum of its sales in each market it serves, and compute the Herfindahl index of firm sales in country $i$. Since the distribution of firm productivities gives rise to a highly skewed distribution of firm sales, there is variation in the Herfindahl index from simulation to simulation, even though we draw as many as 7 million operating firms in a given country - note that this number is the total for the $N$ and $T$ sectors, where we take independent draws for each sector. We thus repeat the exercise 1001 times, and take the median values of the Herfindahl index in each country. In parallel, we also compute the Herfindahl index of firm sales in autarky for each country, which will allow us to gauge the contribution of international trade to aggregate volatility. Given these values of the Herfindahl index $h$, we can then construct each country's aggregate volatility under trade and in autarky using the formula for the standard deviation of aggregate output growth (9) and a realistic value of $\sigma$. Following Gabaix (2011), we set $\sigma=0.1$, although since in this paper we will not exploit any variation in $\sigma$ across countries, 
none of the results will be driven by this choice.

It is worth making a comparison between our procedure and the one adopted by Eaton et al. (2012). Eaton et al. (2012) simulate the firm behavior first, starting with the lowest cost and working their way up. That procedure makes it easier to then calculate entry cutoffs and price indices for each country conditional on the firm-level draws. The advantage of this approach is that in calculating the price index the issue of an exploding integral does not arise even if $\theta_{s}<\varepsilon_{s}-1$. A disadvantage is that, to keep the procedure tractable, Eaton et al. (2012) need to impose additional assumptions so that the total spending in each country and the wage can be taken as exogenous. This would be problematic in our setting, since for us the equilibrium number of entrants is an endogenous, and central, outcome driving the results on the cross-country variation in volatility.

\subsection{Model Fit}

We assess the model fit along three dimensions: (i) overall and bilateral trade volumes; (ii) the relationship between country size and the size of the largest firms in each country; and (iii) the share of exporting firms in the economy.

Figure 6a reports the scatterplot of bilateral trade ratios, $\pi_{i j}=X_{i j} / w_{i} L_{i}$. Note that since in the data we only have bilateral trade as a share of GDP, not of total sales, we compute the same object in the model. This captures both the distinction between trade, which is recorded as total value, and GDP, which is recorded as value added; as well as the fact that there is a large non-traded sector in both the model and in the data. On the horizontal axis is the natural logarithm of $\pi_{i j}$ that comes from the model, while on the vertical axis is the corresponding value of that bilateral trade flow in the data. Hollow dots represent exports from one country to another, $\pi_{i j}, i \neq j$. Solid dots, at the top of the scatterplot, represent sales of domestic firms as a share of domestic absorption, $\pi_{i i}$. It is especially important that we reproduce the variation in the overall trade openness $\left(1-\pi_{i i}\right)$, since that will drive the contribution of trade to the aggregate volatility in each country. Figure $6 \mathrm{~b}$ plots the actual values of $\left(1-\pi_{i i}\right)$ against those implied by the model. For convenience, we add a 45-degree line to both plots.

Table 3 compares the means and medians of $\pi_{i i}$ and $\pi_{i j}$ 's for the model and the data, and reports the correlations between the two. The correlation between domestic shares $\pi_{i i}$ calculated from the model and those in the data for this sample of countries is around 0.48 . The correlation between export shares, $\pi_{i j}$, is actually higher at $0.78 .{ }^{18}$ Since we use esti-

\footnotetext{
${ }^{18}$ We also experimented with increasing the number of countries in the simulation to 60 . The model fits
} 
mated gravity coefficients together with the actual data on bilateral country characteristics to compute trade costs, it is not surprising that bilateral trade flows implied by our model are closely correlated to those in the data given the success of the empirical gravity relationship. Nonetheless, since the gravity estimates we use come from outside of our calibration procedure, it is important to check that our model delivers outcomes similar to observed trade volumes.

We next assess whether the model reproduces the relationships between country size and the relevant features of the firm size distributions demonstrated in Figure 3. In the data, log country size is negatively and significantly related to the log Herfindahl index of firm sales; and positively and significantly related to the size of the 10 largest firms and the size of the largest firm in the economy. We can compare the data to the same relationships inside our model. It turns out that in the model the elasticity of the Herfindahl index with respect to country size is -0.135 , which is right in between the Herfindahl-country size elasticity of -0.114 (sample of countries with more than 1000 firms) and -0.284 (sample of countries with more than 100 firms) in Figure 3a. Turning to the size of the largest firms, our model produces an elasticity of the 10 largest firms to country size of 0.903 , and of the single largest firm to country size of 0.908 . These are close to the range of elasticities produced by the data: 0.888 to 1.006 for the 10 largest firms (Figure 3b), and 0.838 to 0.906 (Figure 3c) for the single largest firm.

Finally, we use the model solution to calculate the percentage of firms that export in the total economy, as well as in the tradeable sector. In particular, the total number of exporters in country $i$ equals $\bar{I}_{i}^{T} \times\left(b_{T} \max _{j \neq i}\left\{a_{j i}^{T}\right\}\right)^{\theta_{T}}$. The total number of firms operating in the tradeable sector equals $\bar{I}_{i}^{T} \times\left(b_{T} \max _{j}\left\{a_{j i}^{T}\right\}\right)^{\theta_{T}}$, and in the non-tradeable sector $\bar{I}_{i}^{N} \times\left(b_{N} a_{i i}^{N}\right)^{\theta_{N}}$. We would like to compare the export participation shares in the model to what is found in the data. Unfortunately, there is no systematic empirical evidence on these shares across countries (and time). However, we have examined available data and existing literature and found these shares for 8 countries: U.S., Germany, France, Argentina, Colombia, Ireland, Chile, and New Zealand. Table 4 compares the export participation shares produced by the model to those found in the data in this subset of countries. The first two columns report the values in the model, with the shares of exporters relative to all the firms in the economy in column 1 and in the tradeable sector only in column 2. Data

the data well, but there are more zeros in bilateral trade data in the 60-country sample compared to the 50-country one. (With 50 countries, among the 2500 possible unidirectional bilateral trade flows, only 18 are zeros.) Since our model does not generate zero bilateral trade outcomes, we stick with the largest 49 countries in our analysis. 
sources differ across countries, in particular the shares of exporting firms are sometimes reported only relative to all firms in the economy (which we record in column 3), and sometimes relative to all the firms in the tradeable sector (which we record in column 4). Thus, data in column 3 should be compared to model outcomes in column 1, while data in column 4 should be compared to model outcomes in column 2.

In both the data and the model, larger countries tend to have fewer exporters relative to the overall number of firms (compare U.S. to Colombia); countries closer to large markets tend to have higher shares of exporters compared to faraway countries (compare Ireland to New Zealand). In most cases the model implied value is close to the data. We should note that by making ad hoc adjustments to trade costs in individual countries, we can match each and every one of these numbers exactly. We do not do so because this information is not available systematically for every country in our sample, and because the available firmlevel data themselves are noisy. Instead, we take trade costs as implied by a basic gravity model, and the variation in fixed costs as implied by the Doing Business Indicators, an approach that is rather straightforward and does not involve any manual second-guessing.

\subsection{Main Results: Country Size and Trade Openness}

As would be expected, the level of aggregate volatility in the model is lower than what is observed in the data, since in the model all volatility comes from idiosyncratic shocks to firms. Column 1 of Table 5 reports the ratio of the aggregate volatility implied by the model to the actual GDP volatility found in the data. It ranges between 0.14 and 0.72 , with a value of 0.377 for the United States, almost identical to what Gabaix (2011) finds using a very different methodology. Note that the variation in aggregate volatility in the model across countries is generated by differences in country size as well as variation in bilateral trade costs.

How well can the model reproduce the empirical relationship between aggregate volatility and country size? Figure 7 plots volatility as a function of country size in the data and the model. Note that since the level of aggregate volatility in the model does not match up with the level in the data, this graph is only informative about the comparison of slopes, not intercepts. In the data the elasticity of GDP volatility with respect to country size is $-0.139\left(\sigma_{\mathrm{GDP}}\right)$ in this sample of countries. Table A1 reports the results of estimating the volatility-size relationship in the data for various country samples and with and without controls. The baseline coefficient used in Figure 7 comes from the 50-country sample and controlling for income per capita. Our calibrated model produces an elasticity of -0.135 
$\left(\sigma_{\mathrm{T}}\right)$, which is extremely close to the one in the data though slightly below it in absolute terms.

We now assess the contribution of international trade to aggregate volatility in our sample of countries. Our model yields not only the aggregate volatility in the simulated trade equilibrium, but also the aggregate volatility in autarky. As a preview of the results on the impact of trade openness, Figure 7 reports the volatility-size relationship in autarky. Without trade this relationship is somewhat flatter: the elasticity of volatility with respect to country size in autarky is $-0.115\left(\sigma_{\mathrm{A}}\right)$, lower than the -0.139 in the data. Thus, it appears that openness helps the model match the slope of the size-volatility relationship: without trade, smaller countries would be relatively less volatile than they actually are.

Column 2 of Table 5 reports the ratio of the volatility under the current trade regime to the volatility in autarky in each country in the sample. In the table, countries are ranked by size in descending order. We can see that international trade contributes very little to overall GDP volatility in the U.S.. The country is so large and trade volumes are so low (relative to total output) that its volatility under trade is only 1.035 times higher than it would be in complete absence of trade. Similar results obtain for other very large economies, such as Japan and China. By contrast, smaller, centrally located countries experience substantially higher volatility compared to autarky. For instance, in a country like Romania, the volatility under trade is some $22 \%$ higher than it would be in autarky, and in Turkey, Denmark, and Norway it is 14-16\% higher. In between are small, but remote countries. South Africa, Argentina, and New Zealand experience aggregate volatility that is about $10 \%$ higher than it would have been in autarky.

Finally, we investigate how well the model predicts the actual GDP volatility found in the data. Table 6 presents regressions of actual volatility of per capita GDP growth over the period 1970-2006 against the one predicted by the model $\left(\sigma_{T}\right)$, with all variables in natural logs. Column 1 includes no controls. The relationship is positive and highly significant. The fit of this simple bivariate relationship is remarkably high $\left(R^{2}=0.353\right)$, given that in the model variation in $\sigma_{T}$ is driven only by country size, trade barriers, and fixed costs. The model uses no information on any type of aggregate shocks (TFP, monetary, or fiscal policy), or any other country characteristics that have been shown to correlate with macroeconomic volatility, such as per capita income, institutions, or industrial specialization. The second column includes GDP per capita. The fit of the model improves slightly, and though the coefficient on the model volatility is somewhat smaller, it remains significant at the $1 \%$ level. The next two columns include measures of export structure volatility and sectoral 
specialization, since di Giovanni and Levchenko (2009, 2012b) show that opening to trade can impact aggregate volatility through changes in these variables. Column 3 adds the risk content of exports, which captures the overall riskiness of a country's export structure. ${ }^{19}$ The model volatility remains significant, and the $R^{2}$ of the regression is now 0.477 . Finally, the fourth column adds a measure of production specialization for the manufacturing sector (Herfindahl of sectoral production shares). ${ }^{20}$ The number of observations drops to 35 due to limited data availability, but the model volatility still remains significant.

\section{Robustness Checks and Model Perturbations}

\subsection{Free Entry and Intermediate Inputs}

The assumption that the number of potential projects is determined by a free entry condition may not be realistic. We thus simulate the quantitative model under the assumption that the numbers of potential entrepreneurs $\bar{I}_{i}^{s}$ are fixed in every country and sector. ${ }^{21}$ Table 7 reports the results of this robustness check. For ease of comparison, the top row presents the two main results from the baseline analysis. The first is that the model generates higher volatility in smaller countries, with the elasticity of volatility with respect to country size of -0.135. (As reported above, in the data this elasticity is very close, -0.139.) The second key result of the paper is the contribution of trade openness to aggregate volatility. Column 2 reports the mean ratio of aggregate volatility under the current level of trade openness relative to complete autarky.

Row 2 of Table 7 reports these two main results of the paper under the alternative assumption that $\bar{I}_{i}^{s}$ is fixed. Not surprisingly, the elasticity of volatility with respect to country size is virtually identical. Less obviously, the fixed- $\bar{I}_{i}^{s}$ model delivers very similar changes in volatility due to trade openness: the mean impact is $9.0 \%$, compared to $9.7 \%$ with free entry.

A somewhat related question involves the role of intermediate input linkages. With intermediate inputs, trade opening reduces the costs of the input bundle faced by firms, making it easier to enter markets, all alse equal. To assess the importance of this effect, we implement the baseline model with free entry but without intermediate input linkages:

\footnotetext{
${ }^{19}$ This measure is taken from di Giovanni and Levchenko (2012b). A country's export structure can be volatile due to a lack of diversification and/or exporting in sectors that are more volatile.

${ }^{20}$ This measure is calculated using the UNIDO database of sectoral production, and is taken from di Giovanni and Levchenko (2009).

${ }^{21}$ We set the values of $\bar{I}_{i}^{s}$ to be the same as in the free entry baseline, and adjust $f_{i i}$ to match the 7 million operating firms in the U.S. in the trade equilibrium; the results are virtually the same if we instead adopt the common ad hoc assumption that $\bar{I}_{i}^{s}$ are some constant fraction of $L_{i}$, as in Chaney (2008), for instance.
} 
$\beta_{T}=\beta_{N}=1$. The two main results are presented in the third row of Table 7 . The elasticity of volatility with respect to country size is only slightly larger than in the baseline, at -0.145 . The impact of trade on volatility is much larger, at $23.8 \%$.

\subsection{Volatility Varying with Firm Size}

An assumption that simplifies the analysis above is that the volatility of the proportional change in sales, $\sigma$, does not change in firm size $x$. If the volatility of sales decreases sufficiently fast in firm size, larger firms will be so much less volatile that they will not impact aggregate volatility. In fact, an economy in which larger firms are just agglomerations of smaller units each subject to i.i.d. shocks is not granular: shocks to firms cannot generate aggregate fluctuations.

In practice, however, the negative relationship between firm size and its sales volatility is not very strong. Several papers estimate the relationship between size and volatility of the type $\sigma=A x^{-\xi}$ using Compustat data (see, e.g., Stanley et al., 1996; Sutton, 2002). The benchmark case in which larger firms are simply collections of independent smaller firms would imply a value of $\xi=1 / 2$, and the absence of granular fluctuations. Instead, the typical estimate of this parameter is about $1 / 6$, implying that larger firms are not substantially less volatile than smaller ones. ${ }^{22}$ Gabaix (2011) argues that these estimates may not be reliable, since they are obtained using only data on the largest listed firms. In addition, it is not clear whether estimates based on the U.S. accurately reflect the experience of other countries. Hence, our baseline analysis sets $\xi=0$, and a value of $\sigma$ based on the largest 100 listed firms in the U.S.. In other words, we assume that all firms in the economy experience volatility as low as the largest firms in the economy.

To check robustness of our results, we allow the firm-specific volatility to decrease in firm size at the rate estimated in the literature. In that case, aggregate volatility is given by

$$
\operatorname{Std}_{z}\left(\frac{\Delta X}{\mathrm{E}_{z}(X)}\right)=\sqrt{\sum_{k=1}^{I}\left(A x(k)^{-\xi} h(k)\right)^{2}},
$$

\footnotetext{
${ }^{22}$ A related point concerns multi-product firms: if large firms sell multiple imperfectly correlated products, then the volatility of the total sales for multi-product firms will be lower than the volatility of single-product firms. Evidence suggests, however, that even in multi-product firms the bulk of sales and exports is accounted for by a single product line. Sutton (2002) provides evidence that in large corporations, the constituent business units themselves follow a power law, with just a few very large business units and many much smaller ones. Along similar lines, Adalet (2009) shows that in the census of New Zealand firms, only about $6.5 \%$ to $9.5 \%$ of sales variation is explained by the extensive margin (more products per firm), with the rest explained by the intensive margin (greater sales per product).
} 
where, once again, $x(k)$ is sales of firm $k$, while $h(k)$ is the share of firm $k$ 's sales in total output in the economy.

The rest of the simulation remains unchanged. Since we are not matching the level of aggregate volatility, just the role of country size and trade, we do not need to posit a value of the constant $A$. However, it would be easy to calibrate to match the volatility of the top 100 firms in the U.S. as reported by Gabaix (2011), for example. Note that compared to the baseline simulation, modelling a decreasing relationship between firm size and volatility is a double-edged sword: while larger firms may be less volatile as a result, smaller firms are actually more volatile. This implies that the impact of either country size or international trade will not necessarily be more muted when we make this modification to the basic model.

Row 4 of Table 7 reports the two main results of the paper under the alternative assumption that firm volatility decreases with firm size. In turns out that in this case, smaller countries are even more volatile relative to large ones (the size-volatility elasticity doubles to -0.286 ), and the contribution of trade is also larger, with trade leading to an average $29 \%$ increase in volatility, compared to $9.7 \%$ in the baseline. Somewhat surprisingly, therefore, allowing volatility to decrease in firm size implies a larger contribution of trade to aggregate volatility, not a smaller one. In fact, this is the case in every country in the sample except the U.S.. ${ }^{23}$

\subsection{Alternative Parameter Values}

We assess the sensitivity of the results in two additional ways. The first is an alternative assumption on the curvature of the firm size distribution. Eaton et al. (2011) estimate a range of values for $\theta /(\varepsilon-1)$ of between 1.5 and 2.5. Though Gabaix (2011) shows that the shocks to large firms can still generate aggregate volatility when the power law exponent is less than 2, it is important to check whether the main results of our paper survive under alternative values of $\theta /(\varepsilon-1)$. Row 5 of Table 7 presents the two main results of the paper

\footnotetext{
${ }^{23}$ Another possible determinant of firm volatility that would be relevant to our analysis is exporting. The baseline model assumes that the volatility of a firm's sales growth does not change when it becomes an exporter. If exporters became systematically more or less volatile than non-exporters, the quantitative results could be affected. To check for this possibility, we used the Compustat Quarterly database of listed U.S. firms together with information on whether a firm is an exporter from the Compustat Segments database. Table A2 estimates the relationship between firm-level volatility - based on either the growth rate of sales or a measure of the "granular residual" following Gabaix (2011) - and its export status and size. Controlling for size, export status is always insignificant, and even the magnitude of the coefficient is exceedingly small, implying that volatility of exporters is between 96 and $99 \%$ of the volatility of non-exporters. Furthermore, the estimated elasticity of volatility with respect to firm size is similar to what is reported in the literature and used in the sensitivity check.
} 
under the assumption that the slope of the power law in firm size is 1.5 instead of 1.06. Though in each case the numbers are slightly smaller in absolute value, the main qualitative and quantitative results remain unchanged: smaller countries still have lower volatility, with elasticity of -0.123 , and trade contributes slightly more to aggregate volatility, with the average increase of $11.6 \%$.

Second, we re-calibrate the model under two alternative values of $\varepsilon, 4$ and 8 . In these exercises, we continue to assume that the economy is characterized by Zipf's Law, so that $\theta /(\varepsilon-1)$ is still equal to our baseline value of 1.06 . Thus, as we change $\varepsilon$, we change $\theta$ along with it. The results are presented in the last two rows of Table 7 . The size-volatility relationship is robust to these alternative assumptions. The elasticity of volatility with respect to country size is similar to the baseline, though slightly lower when $\varepsilon=4$. The contribution of trade is quite similar as well, with $9.9 \%$ and $11.1 \%$ for $\varepsilon=4$ and $\varepsilon=8$, respectively.

Although for all of the robustness checks Table 7 reports only the average impact of trade, it turns out that all of these alternative implementations preserve the basic patterns found in the baseline: trade raises volatility relative to autarky in all countries; larger countries, and countries farther away from major trading partners tend to experience smaller changes in volatility due to trade.

\subsection{Further Reductions in Trade Costs}

The analysis above compares aggregate volatility under today's trade costs and in autarky, and finds that the impact of trade on volatility has been robustly positive. We now evaluate how volatility would change if trade costs decreased further from their current levels. Table 8 presents the distribution of changes in aggregate volatility relative to its current level for various magnitudes of trade cost reductions, from $10 \%$ to $75 \%$. Strikingly, a further reduction in trade costs leads to practically no change in volatility on average. For the median country, a $50 \%$ reduction in trade costs increases volatility by only $1.1 \%$ relative to the baseline. Furthermore, while the median volatility does rise slightly as trade costs fall, the impact always ranges from positive to negative.

What can explain this non-monotonicity? Starting from autarky, as trade costs fall only the largest firms export, and the distribution of firm size becomes more right-skewed. This is the main mechanism responsible for the positive effect of trade openness on volatility. However, as trade costs fall further, the exporting cutoff falls, and more and more firms begin exporting. Eventually, this process will make the firm size distribution less fat-tailed: 
when trade costs are so low that everyone exports, there is no selection into exporting, and the power law in firm size exponent is the same as it was in autarky. Consistent with this intuition, we find that the change in aggregate volatility when trade costs fall is closely correlated with the concomitant change in the share of exporters. Smaller countries tend to experience the largest increases in the share of exporters, and the greatest decreases in volatility in this counterfactual. The opposite is true for the biggest countries.

Two additional points are worth making about the impact of further reductions in trade costs. First, the non-monotonicity is not due to the assumption of free entry: the results are virtually the same if we assume fixed $\bar{I}_{i}^{s}$ instead. Second, in the model without intermediates the non-monotonicity disappears: reductions in trade costs always increase volatility in that model. The source of the difference is that without intermediates, a given fall in trade costs leads to a far smaller change in the exporting cutoffs than in the model with intermediates. Many fewer firms enter the export markets, and thus the selection into exporting effect is not reversed as it is in the baseline. What is the intuition for this difference? In both models, a global fall in $\tau_{i j}$ has the direct effect of lowering the firms' marginal cost of serving the export markets, and thus makes the firm more likely to start selling abroad. In a model with intermediates, there is an additional effect that the fall in $\tau_{i j}$ lowers the cost of the input bundle $c_{j}^{s}$, since that input bundle includes foreign varieties and those are now cheaper. This indirect effect further lowers the exporting cutoffs, over and above the direct effect of $\tau_{i j}$. In the model without intermediates the indirect effect is absent, since the input bundle is just the wage. It turns out that quantitatively this makes a large difference for the results of a reduction in trade costs.

We conclude from these exercises that while the impact of openness on volatility at the current levels of trade costs is robustly positive in all the models we consider, the outcomes of further reductions in trade costs are sensitive to modelling assumptions about intermediate input linkages.

\section{Conclusion}

Recent literature in both macroeconomics and international trade has focused attention on the role of large firms. Gabaix (2011) demonstrates that if the distribution of firm size follows a power law with an exponent close to negative 1 - which appears to be the case in the data - the economy is granular: shocks to the largest firms can lead to aggregate fluctuations.

This paper argues that the preponderance of large firms and their role in aggregate 
volatility can help explain two empirical regularities: (i) smaller countries are more volatile, and (ii) more open countries are more volatile. We calibrate and simulate a multi-country model of firm-level production and trade that can generate granular fluctuations. The model matches quite well a number of features of the data, such as observed bilateral and overall trade volumes, export participation ratios, and the relative size of the largest firms in different countries. We show that the model reproduces the elasticity of GDP volatility with respect to country size found in the data. The contribution of international trade to aggregate volatility varies a great deal depending on country characteristics. While it is minimal in large, relatively closed economies like the U.S. or Japan, trade increases volatility by up to $15-20 \%$ in small open economies such as Denmark or Romania.

Recent research incorporates heterogeneous firms into fully dynamic general equilibrium macroeconomics models, focusing on the impact of persistent aggregate shocks and firm entry and exit (Ghironi and Melitz, 2005; Alessandria and Choi, 2007; Ruhl, 2008). The importance of firm-specific idiosyncratic shocks for macroeconomic volatility via the granular channel emphasized in this paper should be viewed as complementary to this work. Future research incorporating these different mechanisms, as well as bringing disaggregated data to the models, will help provide an even more complete picture of the macroeconomic impact of trade integration.

\section{Appendix A Data Description and Sources}

Data on total GDP, per capita income, and trade openness come from the World Bank's World Development Indicators database (The World Bank, 2007b). Aggregate volatility is the standard deviation of the yearly growth rates of per capita GDP in constant local currency units over the period 1970-2006. Country size is the average share of the country's nominal U.S. dollar GDP in the world U.S. dollar GDP. Per capita income is the average real PPP-adjusted per capita GDP. All the averages are taken over the same period over which the volatility is computed, 1970-2006.

The figures on Fonterra are obtained from http://www.maf.govt.nz/mafnet/rural-nz/ profitability-and-economics/contribution-of-land-based-industries-nz-economic-growth/contribution07. htm and http://tvnz.co.nz/view/page/423466/146647. The data on the 10 largest Korean business groups come from the Korean Development Institute courtesy of Wonhyuk Lim, and are for the year 2006 .

The data on the Herfindahl indices of firm sales and the size of the 10 largest and the single largest firm come from ORBIS, a large multi-country database published by Bureau 
van Dijk that contains information on more than 50 million companies worldwide. The data come from a variety of sources, including, but not limited to, registered filings and annual reports. Importantly, the database includes both publicly traded and privately held firms. The main variable used in the analysis is total sales. For each country, we use the year with the most observations available, which is always between 2006 and 2008. ORBIS is the largest available non-proprietary firm-level database. Nonetheless, coverage is quite uneven across countries and years, implying that measures of concentration may not be reliable or comparable across countries. We alleviate this concern by restricting the sample of countries to those with a certain minimum numbers of firms, and by using indices that are less prone to coverage-related biases. Di Giovanni and Levchenko (2012a) present a more complete description of the ORBIS database and further evidence based on these data that firm size distributions in a large number of countries are extremely fat-tailed.

To obtain values of $\tau_{i j}$, we use the gravity estimates from the empirical model of Helpman et al. (2008). Combining geographical characteristics such as bilateral distance, common border, common language, whether the two countries are in a currency union and others, with the coefficient estimates reported by Helpman et al. (2008) yields, up to a multiplicative constant, the values of $\tau_{i j}$ for each country pair. We vary the multiplicative constant so as to match the mean and median imports/GDP ratios observed in the data in our sample of countries. Data on bilateral distance, common border, whether the country is an island or landlocked, common language, and colonial ties are from Centre d'Etudes Prospectives et Informations Internationales (CEPII). Data on legal origins come from La Porta et al. (1998). Finally, information on currency unions and free-trade areas come from Rose (2004), supplemented by internet searches whenever needed. The advantage of the Helpman et al. (2008) estimates is that they are obtained in an empirical model that accounts explicitly for both fixed and variable costs of exporting, and thus correspond most closely to the theoretical structure in our paper. Note that in this formulation, $\tau_{i j}=\tau_{j i}$ for all $i$ and $j .{ }^{24}$

The values of $f_{i i}^{s}$ and $f_{i j}^{s}$ are calibrated following di Giovanni and Levchenko (2012a). The Doing Business Indicators database (The World Bank, 2007a) collects information on the administrative costs of setting up a firm - the time it takes, the number of procedures, and the monetary cost - in a large sample of countries in the world. The particular variable we use is the amount of time required to set up a business. We favor this indicator compared to others that measure entry costs either in dollars or in units of per capita income, because

\footnotetext{
${ }^{24}$ An earlier version of the paper also computed $\tau_{i j}$ using the estimates of Eaton and Kortum (2002) as a robustness check. The results were very similar.
} 
in our model $f_{i i}^{s}$ is a quantity of inputs rather than a value. We must normalize $f_{i i}^{s}$ for one country. Thus, we proceed by setting $f_{U S, U S}^{s}$ to a level just high enough to ensure an interior solution for production cutoffs. ${ }^{25}$ Then, for every other country $f_{i i}^{s}$ is set relative to the U.S.. To be precise, if according to the Doing Business Indicators database, it takes 10 times longer to register a business in country $i$ than in the U.S., then $f_{i i}^{s}=10 \times f_{U S, U S}^{s}$. Since we do not have data on fixed costs of operating a business that vary by sector, we set $f_{i i}^{s}$ to be equal in the $N$ and $T$ sectors.

To measure the fixed costs of international trade, we use the Trading Across Borders module of the Doing Business Indicators. This module provides the costs of exporting a 20-foot dry-cargo container out of each country, as well as the costs of importing the same kind of container into each country. Parallel to our approach to setting the domestic cost $f_{i i}^{s}$, the indicators we choose are the amount of time required to carry out these transactions. This ensures that $f_{i i}^{T}$ and $f_{i j}^{T}$ are measured in the same units. We take the bilateral fixed cost $f_{i j}^{T}$ to be the sum of the cost of exporting from country $j$ and the cost of importing into country $i$. The foreign trade costs $f_{i j}^{T}$ are on average about $40 \%$ of the domestic entry costs $f_{i i}^{T} \cdot{ }^{26}$

The bilateral and overall trade volumes as a share of GDP used for comparison to the model come from the Direction of Trade Statistics (International Monetary Fund, 2007).

\section{Appendix B The Complete 2-Sector Model}

In country $i$, consumers maximize

$$
\begin{gathered}
\max _{\left\{y_{i}^{N}(k), y_{i}^{T}(k)\right\}}\left(\sum_{k=1}^{J_{i}^{N}} y_{i}^{N}(k)^{\frac{\varepsilon_{N}-1}{\varepsilon_{N}}}\right)^{\frac{\alpha \varepsilon_{N}}{\varepsilon_{N}-1}}\left(\sum_{k=1}^{J_{i}^{T}} y_{i}^{T}(k)^{\frac{\varepsilon_{T}-1}{\varepsilon_{T}}}\right)^{\frac{(1-\alpha) \varepsilon_{T}}{\varepsilon_{T}-1}} \\
\text { s.t. } \\
\sum_{k=1}^{J_{i}^{N}} p_{i}^{N}(k) y_{i}^{N}(k)+\sum_{k=1}^{J_{i}^{T}} p_{i}^{T}(k) y_{i}^{T}(k)=Y_{i},
\end{gathered}
$$

\footnotetext{
${ }^{25}$ That is, we set $f_{U S, U S}^{s}$ to a level just high enough that $a_{j i}^{s}<1 / b_{s}$ for all $i, j=1, \ldots, \mathcal{C}$ in all the baseline and counterfactual exercises, with $1 / b_{s}$ being the upper limit of the distribution of $a$.

${ }^{26} \mathrm{An}$ earlier version of the paper was more agnostic about the nature of domestic fixed costs $f_{i i}^{T}$, and assumed instead that they are equal (and low) in every country. The results were very similar. In addition, we carried out the analysis setting the bilateral fixed cost to be the sum of domestic costs of starting a business in the source and destination countries: $f_{i j}^{T}=f_{i i}^{T}+f_{j j}^{T}$. This approach may be preferred if fixed costs of exporting involved more than just shipping, and required, for instance, the exporting firm to create a subsidiary for the distribution in the destination country. The results were virtually identical.
} 
where $y_{i}^{s}(k)$ is final consumption of good $k$ belonging to sector $s=N, T$ in country $i, p_{i}^{s}(k)$ is the price of this good, $Y_{i}$ is total final consumption expenditure in the economy, and $J_{i}^{s}$ is the number of varieties available in sector $s$ in country $i$ coming from all countries. Since consumer preferences are Cobb-Douglas in CES aggregates of $N$ and $T$, final consumption expenditure on sector $N$ is equal to $\alpha Y_{i}$, and on the $T$ sector, $(1-\alpha) Y_{i}$.

The CES composites of both $N$ and $T$ are used both as consumption and as intermediate inputs in production. Let $X_{i}^{s}$ denote the total spending - final and intermediate - on sector $s=N, T$ in country $i$. Given this total expenditure, it is well known that expenditure on an individual variety $k$ in country $i$ is equal to

$$
x_{i}^{s}(k)=\frac{X_{i}^{s}}{\left(P_{i}^{s}\right)^{1-\varepsilon_{s}}} p_{i}^{s}(k)^{1-\varepsilon_{s}}
$$

where $P_{i}^{s}$ is the ideal price index of sector $s$ in this economy, (2), augmented with the appropriate sector superscripts.

Production in both sectors uses both labor and CES composites of $N$ and $T$ as intermediate inputs. An input bundle in country $j$ and sector $s$ has a cost

$$
c_{j}^{s}=w_{j}^{\beta_{s}}\left[\left(P_{j}^{N}\right)^{\eta_{s}}\left(P_{j}^{T}\right)^{1-\eta_{s}}\right]^{1-\beta_{s}} .
$$

That is, production in sector $s=N, T$ requires labor, inputs of $N$, and inputs of $T$. The share of labor in value added, $\beta_{s}$, and the share of non-tradeable inputs in total input usage, $\eta_{s}$, both vary by sector.

Entrepreneurs can pay the exploration cost $f_{e}$ to enter either sector. Each entrepreneur that entered sector $s$ in country $j$ decides whether or not to pay the fixed cost of production $f_{j j}^{s}$, and which, if any, export markets to serve. In the $N$ sector, we assume that trade costs are infinite, and thus a firm in country $j$ may only serve its own market.

The expressions defining the input requirement cutoffs $a_{i j}^{s}$, (3) and (4), and the free entry conditions (5), have the same form (up to the appropriate sector superscripts) and will hold in each sector. Following similar steps, we derive the expressions for the price levels in the two sectors:

$P_{i}^{N}=\frac{1}{b_{N}}\left[\frac{\theta_{N}}{\theta_{N}-\left(\varepsilon_{N}-1\right)}\right]^{-\frac{1}{\theta_{N}}} \frac{\varepsilon_{N}}{\varepsilon_{N}-1}\left(\frac{X_{i}^{N}}{\varepsilon_{N}}\right)^{-\frac{\theta_{N}-\left(\varepsilon_{N}-1\right)}{\theta_{N}\left(\varepsilon_{N}-1\right)}}\left(\bar{I}_{i}^{N}\left(\frac{1}{c_{i}^{N}}\right)^{\theta_{N}}\left(\frac{1}{c_{i}^{N} f_{i i}^{N}}\right)^{\frac{\theta_{N}-\left(\varepsilon_{N}-1\right)}{\varepsilon_{N}-1}}\right)^{-\frac{1}{\theta_{N}}}$ 
and

$$
P_{i}^{T}=\frac{1}{b_{T}}\left[\frac{\theta_{T}}{\theta_{T}-\left(\varepsilon_{T}-1\right)}\right]^{-\frac{1}{\theta_{T}}} \frac{\varepsilon_{T}}{\varepsilon_{T}-1}\left(\frac{X_{i}^{T}}{\varepsilon_{T}}\right)^{-\frac{\theta_{T}-\left(\varepsilon_{T}-1\right)}{\theta_{T}\left(\varepsilon_{T}-1\right)}}\left(\sum_{j=1}^{\mathcal{C}} \bar{I}_{j}^{T}\left(\frac{1}{\tau_{i j} c_{j}^{T}}\right)^{\theta_{T}}\left(\frac{1}{c_{j}^{T} f_{i j}^{T}}\right)^{\frac{\theta_{T}-\left(\varepsilon_{T}-1\right)}{\varepsilon_{T}-1}}\right)^{-\frac{1}{\theta_{T}}} .
$$

Having expressed $P_{i}^{s}$, and $a_{i j}^{s}$ in terms of $X_{i}^{s}$ and $c_{i}^{s}$ for all $i, j=1, \ldots, \mathcal{C}$, it remains to close the model by solving for the $X_{i}^{s}$ 's and $w_{i}$ 's. To do this, we impose balanced trade for each country and the market clearing conditions in each sector and country. Free entry implies that the total profits are zero, and thus final expenditure in country $i$ simply equals labor income: $Y_{i}=w_{i} L_{i}$. Total expenditure $X_{i}^{N}$ and $X_{i}^{T}$ equals final spending plus expenditure on sector $s$ as intermediate inputs in both sectors:

$$
\begin{aligned}
X_{i}^{N} & =\alpha w_{i} L_{i}+\left(1-\beta_{N}\right) \eta_{N} X_{i}^{N}+\left(1-\beta_{T}\right) \eta_{T} X_{i}^{T} \\
X_{i}^{T} & =(1-\alpha) w_{i} L_{i}+\left(1-\beta_{N}\right)\left(1-\eta_{N}\right) X_{i}^{N}+\left(1-\beta_{T}\right)\left(1-\eta_{T}\right) X_{i}^{T} .
\end{aligned}
$$

Note that even though the $T$ sector has both imports and exports, the assumption that only $T$-sector goods can be traded amounts to imposing balanced trade within the $T$ sector, and thus the second condition must be satisfied in equilibrium as written. These two conditions imply that total spending in each sector is a constant multiple of labor income $w_{i} L_{i}$.

Total sales from country $i$ to country $j$ can be written as

$$
X_{j i}^{T}=\frac{X_{j}^{T}}{\left(P_{j}^{T}\right)^{1-\varepsilon_{T}}}\left(\frac{\varepsilon_{T}}{\varepsilon_{T}-1} \tau_{j i} c_{i}^{T}\right)^{1-\varepsilon_{T}} \bar{I}_{i}^{T} \frac{b_{T}^{\theta_{T}} \theta_{T}}{\theta_{T}-\left(\varepsilon_{T}-1\right)}\left(a_{j i}^{T}\right)^{\theta_{T}-\left(\varepsilon_{T}-1\right)} .
$$

Using expressions for $a_{j i}^{T}$ in (4), and $P_{j}^{T}$ in (B.2), total exports from $i$ to $j$ become

$$
X_{j i}^{T}=\frac{\bar{I}_{i}^{T}\left(\tau_{j i} c_{i}^{T}\right)^{-\theta_{T}}\left(f_{j i}^{T} c_{i}^{T}\right)^{-\frac{\theta_{T}-\left(\varepsilon_{T}-1\right)}{\varepsilon_{T}-1}}}{\sum_{l=1}^{\mathcal{C}} \bar{I}_{l}^{T}\left(\tau_{j l} c_{l}^{T}\right)^{-\theta_{T}}\left(f_{j l}^{T} c_{l}^{T}\right)^{-\frac{\theta_{T}-\left(\varepsilon_{T}-1\right)}{\varepsilon_{T}-1}}} X_{j}^{T} .
$$

Using the trade balance conditions, $X_{i}^{T}=\sum_{j=1}^{\mathcal{C}} X_{j i}^{T}$ for each $i=1, \ldots, \mathcal{C}$, as well as the property that total spending $X_{i}^{T}$ is a constant multiple of $w_{i} L_{i}$ leads to the following system of equations in $w_{i}$ :

$$
w_{i} L_{i}=\sum_{j=1}^{\mathcal{C}} \frac{\bar{I}_{i}^{T} \tau_{j i}^{-\theta_{T}}\left(f_{j i}^{T}\right)^{-\frac{\theta_{T}-\left(\varepsilon_{T}-1\right)}{\varepsilon_{T}-1}}\left(w_{i}^{\beta_{T}}\left[\left(P_{i}^{N}\right)^{\eta_{T}}\left(P_{i}^{T}\right)^{1-\eta_{T}}\right]^{1-\beta_{T}}\right)^{-\theta_{T}-\frac{\theta_{T}-\left(\varepsilon_{T}-1\right)}{\varepsilon_{T}-1}}}{\sum_{l=1}^{\mathcal{C}} \bar{I}_{l}^{T} \tau_{j l}^{-\theta_{T}}\left(f_{j l}^{T}\right)^{-\frac{\theta_{T}-\left(\varepsilon_{T}-1\right)}{\varepsilon_{T}-1}}\left(w_{l}^{\beta_{T}}\left[\left(P_{l}^{N}\right)^{\eta_{T}}\left(P_{l}^{T}\right)^{1-\eta_{T}}\right]^{1-\beta_{T}}\right)^{-\theta_{T}-\frac{\theta_{T}-\left(\varepsilon_{T}-1\right)}{\varepsilon_{T}-1}}} w_{j} L_{j},
$$


$i=1, \ldots, \mathcal{C}$. There are $\mathcal{C}-1$ independent equations in this system, with wage in one of the countries as the numéraire.

A monopolistically competitive equilibrium is a set of prices $\left\{w_{i}, P_{i}^{N}, P_{i}^{T}\right\}_{i=1}^{\mathcal{C}}$, and factor allocations such that (i) consumers maximize utility; (ii) firms maximize profits, and (iii) all goods and factor markets clear. The equilibrium is obtained as a solution to $(\mathcal{C}-1)+2 \times$ $\mathcal{C}+2 \times \mathcal{C}$ equations in $w_{i}, P_{i}^{N}, P_{i}^{T}, \bar{I}_{i}^{N}$ and $\bar{I}_{i}^{T}$ that satisfies equations (5) for both $s=N, T$, (B.1), (B.2), and (B.3) for each $i=1, \ldots, \mathcal{C}$. We solve these equations numerically in order to carry out the main quantitative exercise in this paper.

\section{B.1 Calibrating To Zipf's Law in Firm Size in a Two-Sector Model with Trade}

While Section 3.2 argues that in a one-sector Melitz-Pareto economy, steady-state firm size follows a power law with exponent $\theta /(\varepsilon-1)$, our quantitative model features two sectors, idiosyncratic shocks to firm sales, as well as selection into exporting. This section shows that the aggregate model economy with these additional features will still exhibit Zipf's Law in firm size.

Deriving an aggregate power law in an economy with two sectors involves computing the (counter-)cdf of the following mixture of distributions. Let $Q$ be a random variable that follows a power law with exponent $\zeta_{1}$ with probability $p$, and with exponent $\zeta_{2}$ with probability $1-p$. It is straightforward to show that the counter-cdf of $Q$ is equal to: $\operatorname{Pr}(Q>q)=p D_{1} q^{-\zeta_{1}}+(1-p) D_{2} q^{-\zeta_{2}}$. Importantly, when $\zeta_{1}=\zeta_{2}=\zeta, Q$ is itself a power law with exponent $\zeta$. This means that a two-sector economy in which both sectors follow a power law with the same exponent will, in aggregate, also exhibit a power law with that exponent. Our quantitative exercise adopt the assumption that both the $N$ and $T$ sectors follow Zipf's Law. Though we are not aware of any comprehensive set of estimates of power law exponents in both traded and non-traded sectors, di Giovanni et al. (2011) estimate power law exponents for a wide range of both traded and non-traded industries using a census of French firms, and find that power law exponents do not differ systematically between traded and non-traded sectors. It still could be the case that while the reduced form exponents - which correspond to $\theta_{T} /\left(\varepsilon_{T}-1\right)$ and $\theta_{N} /\left(\varepsilon_{N}-1\right)$ - are the same, the actual values of $\theta_{s}$ and $\varepsilon_{s}$ differ. Since we do not have reliable information about how these two individual parameters differ across sectors, we adopt the most agnostic and neutral assumption that both $\theta_{s}$ and $\varepsilon_{s}$ are the same in the two sectors.

Another concern is that even if steady-state firm size in the aggregate economy follows Zipf's Law, when firms are hit by idiosyncratic shocks $z$, the resulting distribution would be something else. It turns out, however, that power laws are preserved under multiplication by a random variable with finite variance. That is, if firm sales are driven by a random productivity that generates Zipf's Law (1/a in our notation), and a finite variance shock $(z)$, the resulting distribution of sales is still Zipf (Gabaix, 2009, pp. 258-259).

Another point regarding the calibration of power law parameters is that strictly speaking, when not all firms export, selection into exporting implies that the power law exponent estimated on total sales - domestic plus exporting - is lower than $\theta /(\varepsilon-1)$. Di Giovanni et al. (2011) explore this bias in detail using the census of French firms, and suggest several corrections to the estimating procedure that can be used to estimate $\theta /(\varepsilon-1)$ in an 
internally consistent way. Their analysis shows that the bias introduced by selection into exporting is not large. Corrected estimates obtained by di Giovanni et al. (2011) show that $\theta /(\varepsilon-1)$ is about 1.05 , roughly the same as the value used in the quantitative exercise.

Thus, even though the model is enriched with these additional features, the resulting distribution of firm size that the model produces still follows Zipf's Law.

\section{Appendix C Aggregate Volatility Derivation}

Firm $k$ in country $i$ with unit input requirement $a(k)$ and realization of transitory shock $z(k)$ has sales of

$$
\begin{aligned}
x^{s}(a(k), z(k)) & =\sum_{j=1}^{\mathcal{C}} \mathbf{1}\left[a(k) \leq a_{i j}\right] \frac{X_{j}^{s}}{\left(P_{j}^{s}\right)^{1-\varepsilon_{s}}}\left(\frac{\varepsilon_{s}}{\varepsilon_{s}-1} \tau_{j i} c_{i}^{s} a(k) z(k)\right)^{1-\varepsilon_{s}} \\
& =\left[\sum_{j=1}^{\mathcal{C}} \mathbf{1}\left[a(k) \leq a_{i j}\right] \frac{X_{j}^{s}}{\left(P_{j}^{s}\right)^{1-\varepsilon_{s}}}\left(\frac{\varepsilon_{s}}{\varepsilon_{s}-1} \tau_{j i} c_{i}^{s} a(k)\right)^{1-\varepsilon_{s}}\right] \tilde{z},
\end{aligned}
$$

where $\mathbf{1}[\cdot]$ is the indicator function that captures whether firm $k$ serves market $j$, and $\tilde{z} \equiv$ $z^{1-\varepsilon_{s}}$. We already assumed that $\mathrm{E}_{z}(\tilde{z})=1$, and now we further suppose that $\operatorname{Var}_{z}(\tilde{z})=\sigma^{2}$. Expected sales for the firm with productivity $a(k)$ are

$$
\mathrm{E}_{z}\left[x^{s}(a(k), z(k))\right]=\sum_{j=1}^{\mathcal{C}} \mathbf{1}\left[a(k) \leq a_{i j}\right] \frac{X_{j}^{s}}{\left(P_{j}^{s}\right)^{1-\varepsilon_{s}}}\left(\frac{\varepsilon_{s}}{\varepsilon_{s}-1} \tau_{j i} c_{i}^{s} a(k)\right)^{1-\varepsilon_{s}} .
$$

Given the expression for the actual sales of the firm with a transitory shock $z(k)$ in (C.1) and the expected sales of the firm with productivity $a(k)$ in (C.2), the actual sales as an approximation around $\mathrm{E}_{z}\left[x^{s}(a(k), z(k))\right]$ are

$$
x^{s}(a(k), z(k)) \approx \mathrm{E}_{z}\left[x^{s}(a(k), z(k))\right]+\left.\frac{d x}{d \tilde{z}}\right|_{\tilde{z}=1} \Delta \tilde{z} .
$$

Therefore, the proportional change in $x^{s}(a(k), z(k))$, or the growth rate, is given by

$$
\frac{\Delta x^{s}(a(k), z(k))}{\mathrm{E}_{z}\left(x^{s}(a(k), z(k))\right)}=\tilde{z}-1
$$

and the variance of this growth rate is

$$
\operatorname{Var}_{z}\left(\frac{\Delta x^{s}(a(k), z(k))}{\mathrm{E}_{z}\left(x^{s}(a(k), z(k))\right)}\right)=\sigma^{2},
$$

which we assume for simplicity is the same in the two sectors $s=N, T$. Dropping the sector superscripts, the total sales in the economy are given by (8), thus the change in the total sales relative to the non-stochastic steady state (the growth rate) is

$$
\frac{\Delta X}{\mathrm{E}_{z} X}=\frac{\sum_{k=1}^{I} \Delta x(a(k), z(k))}{\mathrm{E}_{z} X}=\sum_{k=1}^{I} \frac{\Delta x(a(k), z(k))}{\mathrm{E}_{z}[x(a(k), z(k))]} \frac{\mathrm{E}_{z}[x(a(k), z(k))]}{\mathrm{E}_{z} X} .
$$


This means that the aggregate volatility is

$$
\begin{aligned}
\operatorname{Var}_{z}\left(\frac{\Delta X}{\mathrm{E}_{z} X}\right) & =\operatorname{Var}_{z}\left(\sum_{k=1}^{I} \frac{\Delta x(a(k), z(k))}{\mathrm{E}_{z}[x(a(k), z(k))]} \frac{\mathrm{E}_{z}[x(a(k), z(k))]}{\mathrm{E}_{z} X}\right) \\
& =\sum_{k=1}^{I} \operatorname{Var}_{z}\left(\frac{\Delta x(a(k), z(k))}{\mathrm{E}_{z}[x(a(k), z(k))]}\right)\left(\frac{\mathrm{E}_{z}[x(a(k), z(k))]}{\mathrm{E}_{z} X}\right)^{2} \\
& =\sigma^{2} \sum_{k=1}^{I}\left(\frac{\mathrm{E}_{z}[x(a(k), z(k))]}{\mathrm{E}_{z} X}\right)^{2} \\
& =\sigma^{2} \sum_{k=1}^{I} h(k)^{2},
\end{aligned}
$$

where $h(k)$ is the share of the firm $k$ 's expected sales in total expected sales in the economy. As expected, the volatility of total output in the economy is equal to the volatility of an individual firm's output times the Herfindahl index of production shares.

\section{References}

Adalet, Müge, "Multi-Product Exporters and Product Turnover Behaviour of New Zealand Firms," April 2009. New Zealand Treasury Working Paper 09/01.

Alessandria, George and Horag Choi, "Do Sunk Costs of Exporting Matter for Net Export Dynamics?," Quarterly Journal of Economics, 2007, 122 (1), 289-336.

Alvarez, Fernando and Robert E. Lucas Jr., "General Equilibrium Analysis of the EatonKortum Model of International Trade," Journal of Monetary Economics, September 2007, 54 (6), 1726-1768.

Anderson, James and Eric van Wincoop, "Trade Costs," Journal of Economic Literature, 2004, 42 (3), 691-751.

Arndt, Christian, Claudia Buch, and Anselm Mattes, "Barriers to Internationalization: Firm-Level Evidence from Germany," September 2009. IAW Discussion Paper 52.

Axtell, Robert L., "Zipf Distribution of U.S. Firm Sizes," Science, September 2001, 293 (5536), 1818-1820.

Backus, David K., Patrick J. Kehoe, and Finn E. Kydland, "International Business Cycles: Theory and Evidence," in Thomas Cooley, ed., Frontiers of Business Cycle Research, Princeton: Princeton University Press, 1995, pp. 331-356.

Barlevy, Gadi, "The Costs of Business Cycles Under Endogenous Growth," American Economic Review, September 2004, 94 (4), 964-990.

Bernard, Andrew B., J. Bradford Jensen, and Peter Schott, "Falling Trade Costs, Heterogeneous Firms, and Industry Dynamics," April 2003. NBER Working Paper No. 9639.

Bernard, Andrew B., J. Bradford Jensen, Stephen Redding, and Peter Schott, "Firms in International Trade," Journal of Economic Perspectives, 2007, 21, 105-130. 
Blattman, Christopher, Jason Hwang, and Jeffrey G. Williamson, "Winners and Losers in the Commodity Lottery: The Impact of Terms of Trade Growth and Volatility in the Periphery 1870-1939," Journal of Development Economics, January 2007, 82 (1), 156-179.

Bustos, Paula, "Trade Liberalization, Exports and Technology Upgrading: Evidence on the impact of MERCOSUR on Argentinean Firms," American Economic Review, March 2011, 101 (1), 304-340.

Canals, Claudia, Xavier Gabaix, Josep M. Vilarrubia, and David E. Weinstein, "Trade Patterns, Trade Balances, and Idiosyncratic Shocks," 2007. la Caixa Working Paper $02 / 2007$.

Canning, D., L.A.N. Amaral, Y. Lee, M. Meyer, and H.E. Stanley, "Scaling the Volatility of GDP Growth Rates," Economics Letters, 1998, 60, 335-341.

Cebeci, Tolga, Ana M. Fernandes, Caroline Freund, and Martha Denisse Pierola, "Exporter Dynamics Database," May 2012. mimeo, The World Bank.

Chaney, Thomas, "Distorted Gravity: The Intensive and Extensive Margins of International Trade," American Economic Review, September 2008, 98 (4), 1707-1721.

Crucini, Mario J., "Country Size and Economic Fluctuations," Review of International Economics, May 1997, 5 (2), 204-220.

Delli Gatti, Domenico, Corrado Di Guilmi, Edoardo Gaffeo, Gianfranco Giulioni, Mauro Gallegati, and Antonio Palestrini, "A New Approach to Business Fluctuations: Heterogeneous Interacting Agents, Scaling Laws and Financial Fragility," Journal of Economic Behavior and Organization, April 2005, 56 (4), 489-512.

di Giovanni, Julian and Andrei A. Levchenko, "Trade Openness and Volatility," Review of Economics and Statistics, August 2009, 91 (3), 558-585.

_ and _, "Firm Entry, Trade, and Welfare in Zipf's World," June 2012. Forthcoming, Journal of International Economics.

_ and _, "The Risk Content of Exports: a Portfolio View of International Trade," NBER International Seminar on Macroeconomics, May 2012, 8 (1), 97-151.

_ , _, and Romain Rancière, "Power Laws in Firm Size and Openness to Trade: Measurement and Implications," Journal of International Economics, September 2011, 85 (1), $42-52$.

Dixit, Avinash K. and Joseph E. Stiglitz, "Monopolistic Competition and Optimum Product Diversity," American Economic Review, June 1977, 67 (3), 297-308.

_ and _, "Monopolistic Competition and Optimum Product Diversity: Reply," American Economic Review, March 1993, 83 (1), 302-304.

Easterly, William, Roumeen Islam, and Joseph E. Stiglitz, "Shaken and Stirred: Explaining Growth Volatility," in B. Pleskovic and N. Stern, eds., Annual World Bank Conference on Development Economics, 2001.

Eaton, Jonathan and Samuel S. Kortum, "Technology, Geography, and Trade," Econometrica, September 2002, 70 (5), 1741-1779.

_, _, and Francis Kramarz, "An Anatomy of International Trade: Evidence from French Firms," Econometrica, September 2011, 79 (5), 1453-1498. 
_ , _, and Sebastian Sotelo, "International Trade: Linking Micro and Macro," February 2012. NBER Working Paper No. 17864.

Fabling, Richard and Lynda Sanderson, "Firm Level Patterns in Merchandise Trade," May 2008. New Zealand Ministry of Economic Development Occasional Paper 08/03.

Fitzgerald, Doireann and Stefanie Haller, "Pricing-to-Market: Evidence From Plant-Level Prices," September 2010. Mimeo, Stanford University and ESRI.

Fujita, Masahisa, Paul Krugman, and Anthony J. Venables, The Spatial Economy: Cities, Regions, and International Trade, Cambridge, Mass.: The MIT Press, 2001.

Furceri, Davide and Georgios Karras, "Country Size and Business Cycle Volatility: Scale Really Matters," Journal of the Japanese and International Economies, 2007, 21 (4), 424-434.

Gabaix, Xavier, "Power Laws in Economics and Finance," Annual Reviews of Economics, 2009, 1, 255-93.

_ , "The Granular Origins of Aggregate Fluctuations," Econometrica, May 2011, 79 (3), $733-772$.

Gavin, Michael and Ricardo Hausmann, "Growth with Equity: The Volatility Connection," in Nancy Birdsall, Carol Graham, and Richard H. Sabot, eds., Beyond Tradeoffs: Market Reforms and Equitable Growth in Latin America, Washington, DC: Inter-American Development Bank and the Brookings Institution, 1998, pp. 91-109.

Ghironi, Fabio and Marc J. Melitz, "International Trade and Macroeconomic Dynamics with Heterogeneous Firms," Quarterly Journal of Economics, August 2005, 120 (3), 865-915.

Head, Allen C., "Country Size, Aggregate Fluctuations, and International Risk Sharing," Canadian Journal of Economics, November 1995, 28 (4b), 1096-1119.

Helpman, Elhanan, Marc J. Melitz, and Yona Rubinstein, "Estimating Trade Flows: Trading Partners and Trading Volumes," Quarterly Journal of Economics, May 2008, 123 (2), 441-487.

Holmes, Thomas J. and John J. Stevens, "An Alternative Theory of the Plant Size Distribution with an Application to Trade," April 2010. Mimeo, University of Minnesota and Federal Reserve Board of Governors.

International Monetary Fund, "Directions of Trade Statistics," 2007.

Katzenstein, Peter J., Small States in World Markets: Industrial Policy in Europe, Ithaca and London: Cornell University Press, 1985.

Koren, Miklós and Silvana Tenreyro, "Volatility and Development," Quarterly Journal of Economics, February 2007, 122 (1), 243-287.

Kose, M. Ayhan, Eswar S. Prasad, and Marco E. Terrones, "Financial Integration and Macroeconomic Volatility," IMF Staff Papers, 2003, 50 (Special Issue), 119-141.

Kraay, Aart and Jaume Ventura, "Comparative Advantage and the Cross-Section of Business Cycles," Journal of European Economic Association, December 2007, 5 (6), 13001333.

Krugman, Paul, "Scale Economies, Product Differentiation, and the Pattern of Trade," American Economic Review, 1980, 70 (5), 950-959. 
La Porta, Rafael, Florencio Lopez de Silanes, Andrei Shleifer, and Robert W. Vishny, "Law and Finance," Journal of Political Economy, December 1998, 106 (6), 1113-1155.

Laursen, Thomas and Sandeep Mahajan, "Volatility, Income Distribution, and Poverty," in Joshua Aizenman and Brian Pinto, eds., Managing Economic Volatility and Crises: A Practitioner's Guide, Cambridge University Press New York 2005, pp. 101-136.

Melitz, Marc J., "The Impact of Trade on Intra-Industry Reallocations and Aggregate Industry Productivity," Econometrica, November 2003, 71 (6), 1695-1725.

Newbery, David M. G. and Joseph E. Stiglitz, "Pareto Inferior Trade," Review of Economic Studies, January 1984, 51 (1), 1-12.

OECD, "The Rise of China and India: What's in it for Africa?," Technical Report, Organization of Economic Cooperation and Development, Development Centre Studies 2006.

Pallage, Stéphane and Michel A. Robe, "On The Welfare Cost of Economic Fluctuations in Developing Countries," International Economic Review, May 2003, 44 (2), 677-698.

Pavcnik, Nina, "Trade Liberalization, Exit, and Productivity Improvements: Evidence from Chilean Plants," Review of Economic Studies, January 2002, 69 (1), 245-276.

Ramey, Garey and Valerie A. Ramey, "Cross-Country Evidence on the Link Between Volatility and Growth," American Economic Review, December 1995, 85 (5), 1138-1151.

Rose, Andrew K., "Do We Really Know That the WTO Increases Trade?," American Economic Review, March 2004, 94 (1), 98-114.

Ruhl, Kim J., "The International Elasticity Puzzle," 2008. mimeo, NYU Stern School of Business.

Stanley, Michael H.R., Luis A.N. Amaral, Sergey V. Buldyrev, Shlomo Havlin, Heiko Leschhorn, Philipp Maass, Michael A. Salinger, and H. Eugene Stanley, "Scaling Behaviour in the Growth of Companies," Nature, February 1996, 379, 804-806.

Sutton, John, "The Variance of Firm Growth Rates: the 'Scaling' Puzzle," Physica A, 2002, $312,577-590$.

The World Bank, "Doing Business Indicators," 2007.

_ , "World Development Indicators," 2007.

Yang, Xiaokai and Ben J. Heijdra, "Monopolistic Competition and Optimum Product Diversity: Comment," American Economic Review, March 1993, 83 (1), 295-301.

Yi, Kei-Mu and Jing Zhang, "Structural Change in an Open Economy," April 2010. Mimeo, Federal Reserve Bank of Philadelphia and University of Michigan. 
Table 1. Parameter Values for the Calibrated Model

\begin{tabular}{|c|c|c|}
\hline Parameter & Baseline & Source \\
\hline$\varepsilon^{\mathrm{a}}$ & 6 & Anderson and van Wincoop (2004) \\
\hline$\theta \mathrm{b}$ & 5.3 & Axtell (2001): $\frac{\theta}{\varepsilon-1}=1.06$ \\
\hline$\alpha$ & 0.65 & Yi and Zhang (2010) \\
\hline$\left\{\beta_{N}, \beta_{T}\right\}$ & $\{0.65,0.35\}$ & \multirow{2}{*}{1997 U.S. Benchmark Input-Output Table } \\
\hline$\left\{\eta_{N}, \eta_{T}\right\}$ & $\{0.77,0.35\}$ & \\
\hline$\tau_{i j}{ }^{\mathrm{c}, \mathrm{d}}$ & 2.30 & Helpman et al. (2008) \\
\hline$f_{i i}{ }^{\mathrm{c}}$ & 14.24 & The World Bank (2007a); normalizing $f_{U S, U S}$ \\
\hline$f_{i j}{ }^{\mathrm{c}}$ & 7.20 & so that nearly all firms in the U.S. produce \\
\hline$f_{e}$ & 34.0 & $\begin{array}{l}\text { To match 7,000,000 firms in the U.S. } \\
\text { (U.S. Economic Census) }\end{array}$ \\
\hline$\sigma^{\mathrm{e}}$ & 0.1 & $\begin{array}{l}\text { Standard deviation of sales growth of the top } \\
100 \text { firms in COMPUSTAT }\end{array}$ \\
\hline
\end{tabular}

Notes:

${ }^{\mathrm{a}}$ Robustness checks include $\varepsilon=4$ and $\varepsilon=8$.

b Robustness checks include $\frac{\theta}{\varepsilon-1}=1.5$ and $\varepsilon=6$, so that $\theta=6.5$.

${ }^{\mathrm{c}}$ Average in our sample of 50 countries.

${ }^{\mathrm{d}} \tau_{i j}=\tau_{j i}$. Trade costs are adjusted by a constant ratio to match the median-level of openness across the 50-country sample.

${ }^{\text {e }}$ Robustness checks include $\sigma$ varying with firm sales: $\sigma=A x^{-\xi}$, where $\xi=1 / 6$. 
Table 2. Top 49 Countries and the Rest of the World in Terms of 2006 GDP

\begin{tabular}{|c|c|c|c|}
\hline & $\overline{\mathrm{GDP} /}$ & & $\overline{\mathrm{GGDP} /}$ \\
\hline Country & World GDP & Country & World GDP \\
\hline United States & 0.300 & Indonesia & 0.006 \\
\hline Japan & 0.124 & South Africa & 0.006 \\
\hline Germany & 0.076 & Norway & 0.006 \\
\hline France & 0.054 & Poland & 0.005 \\
\hline United Kingdom & 0.044 & Finland & 0.005 \\
\hline Italy & 0.041 & Greece & 0.004 \\
\hline China & 0.028 & Venezuela, RB & 0.004 \\
\hline Canada & 0.026 & Thailand & 0.004 \\
\hline Brazil & 0.021 & Portugal & 0.003 \\
\hline Spain & 0.020 & Colombia & 0.003 \\
\hline India & 0.017 & Nigeria & 0.003 \\
\hline Australia & 0.016 & Algeria & 0.003 \\
\hline Russian Federation & 0.015 & Israel & 0.003 \\
\hline Mexico & 0.015 & Philippines & 0.003 \\
\hline Netherlands & 0.015 & Malaysia & 0.002 \\
\hline Korea, Rep. & 0.011 & Ireland & 0.002 \\
\hline Sweden & 0.010 & Egypt, Arab Rep. & 0.002 \\
\hline Switzerland & 0.010 & Pakistan & 0.002 \\
\hline Belgium & 0.009 & Chile & 0.002 \\
\hline Argentina & 0.008 & New Zealand & 0.002 \\
\hline Saudi Arabia & 0.007 & Czech Republic & 0.002 \\
\hline Austria & 0.007 & United Arab Emirates & 0.002 \\
\hline Iran, Islamic Rep. & 0.007 & Hungary & 0.002 \\
\hline Turkey & 0.007 & Romania & 0.002 \\
\hline Denmark & 0.006 & Rest of the World & 0.027 \\
\hline
\end{tabular}

Notes: Ranking of top 49 countries and the rest of the world in terms of 2006 U.S.\$ GDP. We include Hong Kong, POC, and Singapore in Rest of the World. Source: The World Bank (2007b). 
Table 3. Bilateral Trade Shares: Data and Model Predictions

\begin{tabular}{ccc}
\hline \hline & Model & Data \\
\cline { 2 - 3 } Domestic sales as a share of GDP $\left(\pi_{i i}\right)$ & 0.7900 & 0.7520 \\
mean & 0.7717 & 0.7921 \\
median & 0.4783 \\
corr(model,data) & & \\
Imports as a share of GDP $\left(\pi_{i j}\right)$ & 0.0043 & 0.0047 \\
mean & 0.0021 & 0.0047 \\
median & 0.7799 \\
corr(model,data)
\end{tabular}

Notes: This table reports the means and medians of domestic output (top panel), and bilateral trade (bottom panel), both as a share of domestic GDP, in the model and in the data. Source: International Monetary Fund (2007).

Table 4. Export Participation: Data and Model Predictions for Whole Economy and Tradeable Sector

\begin{tabular}{|c|c|c|c|c|}
\hline \multirow[b]{3}{*}{ Country } & (1) & $(2)$ & $(3)$ & $(4)$ \\
\hline & \multicolumn{2}{|c|}{ Model } & \multicolumn{2}{|c|}{ Data } \\
\hline & Total & Tradeable & Total & Tradeable \\
\hline United States & 0.010 & 0.018 & 0.040 & 0.150 \\
\hline Germany & 0.111 & 0.238 & 0.100 & $\ldots$ \\
\hline France & 0.029 & 0.065 & 0.040 & 0.090 \\
\hline Argentina & 0.112 & 0.352 & $\ldots$ & 0.422 \\
\hline Colombia & 0.148 & 0.548 & $\ldots$ & 0.363 \\
\hline Ireland & 0.332 & 1.000 & $\ldots$ & 0.740 \\
\hline Chile & 0.095 & 0.335 & 0.105 & $\ldots$ \\
\hline New Zealand & 0.062 & 0.189 & 0.051 & 0.135 \\
\hline
\end{tabular}

Notes: This table compares, for selected countries, the share of exporters among all firms in the model (column 1) and the share of exporters among the tradeable sector firms in the model (column 2) with available estimates of corresponding shares in existing literature. Since for some countries, data are reported relative to all the firms in the economy, while for other countries it is reported relative to all the firms in the traded sector, column 3 (data) should be compared to column 1 (model), and column 4 (data) should be compared to Column 2 (model). For the United States, data are imputed based on publicly available U.S. Economic Census data on the numbers of firms by sector, together with the summary statistics for the numbers of exporters reported in Bernard et al. (2007). Data for France is based on authors' calculations using the French Census data in di Giovanni et al. (2011). Data for Germany are from Arndt et al. (2009) (Table A2). Data for Argentina come from Bustos (2011), Table D.1. For New Zealand, data come from Fabling and Sanderson (2008), Table 4. Data on Ireland come from Fitzgerald and Haller (2010), Table 1. Data for Chile come from private communication with Miguel Fuentes at the Central Bank of Chile. Data for Colombia come from private communication with Jorge Tovar at the Universidad de los Andes. 


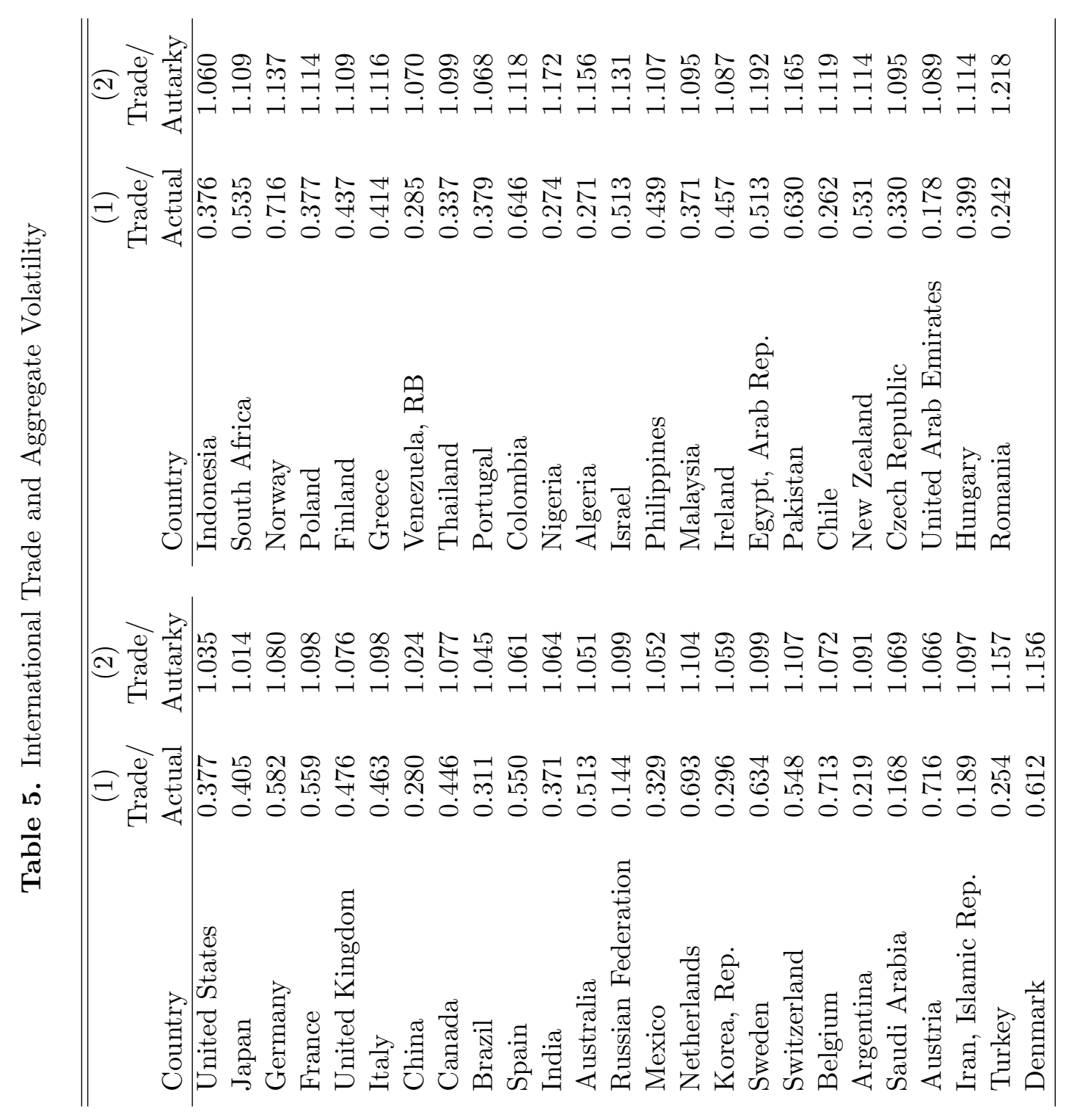

我要

焉

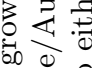

$50 \frac{8}{\pi}+$

藏串

苋宽离

ช $\mid 1$

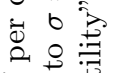

西

형

黛.

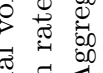

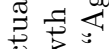

\%

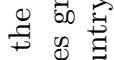

윰유

苛胥

密苛

寻岁密

ब

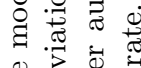

焉要

3. 흘

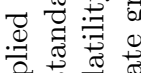

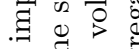

声先

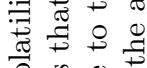

8 \&

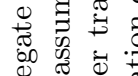

品

\% छ

पㄷㅇㅇ

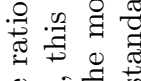

过

원

过总

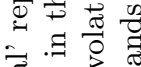

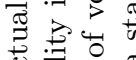

出营. 要

ष웡

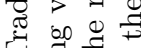

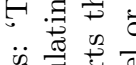

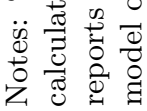


Table 6. Aggregate Volatility: Data and Model Predictions

\begin{tabular}{lcccc}
\hline \hline & $(1)$ & $(2)$ & $(3)$ & $(4)$ \\
\cline { 2 - 5 } Dep. Var: $\log ($ GDP Volatility) & & & \\
$\log \left(\sigma_{T}\right)$ & $1.578^{* *}$ & $1.365^{* *}$ & $1.099^{* *}$ & $0.765^{* *}$ \\
& $(0.244)$ & $(0.321)$ & $(0.287)$ & $(0.274)$ \\
$\log ($ GDP per capita) & & -0.093 & -0.098 & $-0.146^{*}$ \\
& & $(0.073)$ & $(0.065)$ & $(0.060)$ \\
$\log ($ Risk Content of Exports) & & & $0.100+$ & -0.064 \\
& & & $(0.053)$ & $(0.052)$ \\
$\log ($ Herfindahl of Production) & & & & -0.134 \\
& $3.490^{* *}$ & $3.417^{* *}$ & $2.994^{* *}$ & $0.217)$ \\
Constant & $(1.092)$ & $(1.145)$ & $(1.079)$ & $(1.045)$ \\
& 49 & 49 & 47 & 35 \\
\hline Observations & 0.353 & 0.378 & 0.477 & 0.450 \\
$R^{2}$ & & & & \\
\hline
\end{tabular}

Notes: The dependent variable is the standard deviation of per capita GDP growth over the period 19702006. $\sigma_{T}$ is the aggregate volatility implied by the simulated model. GDP per capita is the PPP-adjusted per capita GDP. Risk Content of Exports is the measure of the volatility of a country's export pattern taken from di Giovanni and Levchenko (2012b). Herfindahl of Production is the Herfindahl index of industry-level production shares, taken from di Giovanni and Levchenko (2009). Robust standard errors in parentheses. + significant at $10 \% ; *$ significant at $5 \% ; * *$ significant at $1 \%$.

Table 7. Sensitivity Checks: The Impact of Country Size and Trade on Volatility

\begin{tabular}{lccc}
\hline \hline & \multicolumn{1}{c}{$(1)$} & & $(2)$ \\
& $\beta_{\text {Size }}$ & & Trade/Autarky \\
Baseline & -0.135 & & 1.097 \\
Fixed $\bar{I}_{i}^{s}$ & & & \\
$\beta_{T}=\beta_{N}=1$ & -0.133 & & 1.090 \\
$\sigma=A x^{-\xi}$ & -0.145 & & 1.238 \\
$\zeta=1.5$ & -0.286 & & 1.291 \\
$\varepsilon=4$ & -0.123 & & 1.116 \\
$\varepsilon=8$ & -0.119 & & 1.099 \\
\hline
\end{tabular}

Notes: This table reports (1) the coefficient of regressing the log of aggregate volatility on the log of country size $\left(\beta_{\text {Size }}\right)$ in the trade equilibrium, and (2) the contribution of international trade to aggregate volatility (the mean ratio of volatility under trade to the volatility in autarky) under alternative assumptions. Row 1 reports the results for the baseline trade equilibrium simulation. Row 2 reports the results of a simulation without free entry. Row 3 reports the results of a simulation without intermediates. Row 4 reports the results of a simulation in which the firm-specific volatility decreases in firm size. Row 5 reports the results of applying a power law coefficient of 1.5 rather than the baseline of 1.06 . Rows 6 and 7 report the results when using an elasticity of substitution of 4 or 8 , respectively. 
Table 8. The Impact of Further Reductions in Trade Costs on Aggregate Volatility

\begin{tabular}{|c|c|c|c|c|}
\hline \multirow[b]{4}{*}{ Percentile } & (1) & $(2)$ & $(3)$ & $(4)$ \\
\hline & \multicolumn{3}{|c|}{ Percentage Reduction in Trade } & Costs \\
\hline & $10 \%$ & $25 \%$ & $50 \%$ & $75 \%$ \\
\hline & & & & \\
\hline 5 & 0.998 & 0.994 & 0.984 & 1.003 \\
\hline 10 & 0.998 & 0.998 & 0.991 & 1.006 \\
\hline 25 & 1.001 & 1.003 & 1.001 & 1.017 \\
\hline 50 & 1.004 & 1.011 & 1.011 & 1.034 \\
\hline 75 & 1.011 & 1.022 & 1.036 & 1.075 \\
\hline 95 & 1.019 & 1.036 & 1.055 & 1.129 \\
\hline $\min$ & 0.995 & 0.988 & 0.973 & 0.990 \\
\hline $\max$ & 1.030 & 1.050 & 1.084 & 1.167 \\
\hline
\end{tabular}

Notes: This table reports percentiles and minimum and maximum of the ratio of aggregate volatility under a four reductions in iceberg trade $\operatorname{costs} \tau_{i j}$ to the aggregate volatility as implied by the model under current trade costs. 
Figure 1. Country Size and Aggregate Volatility

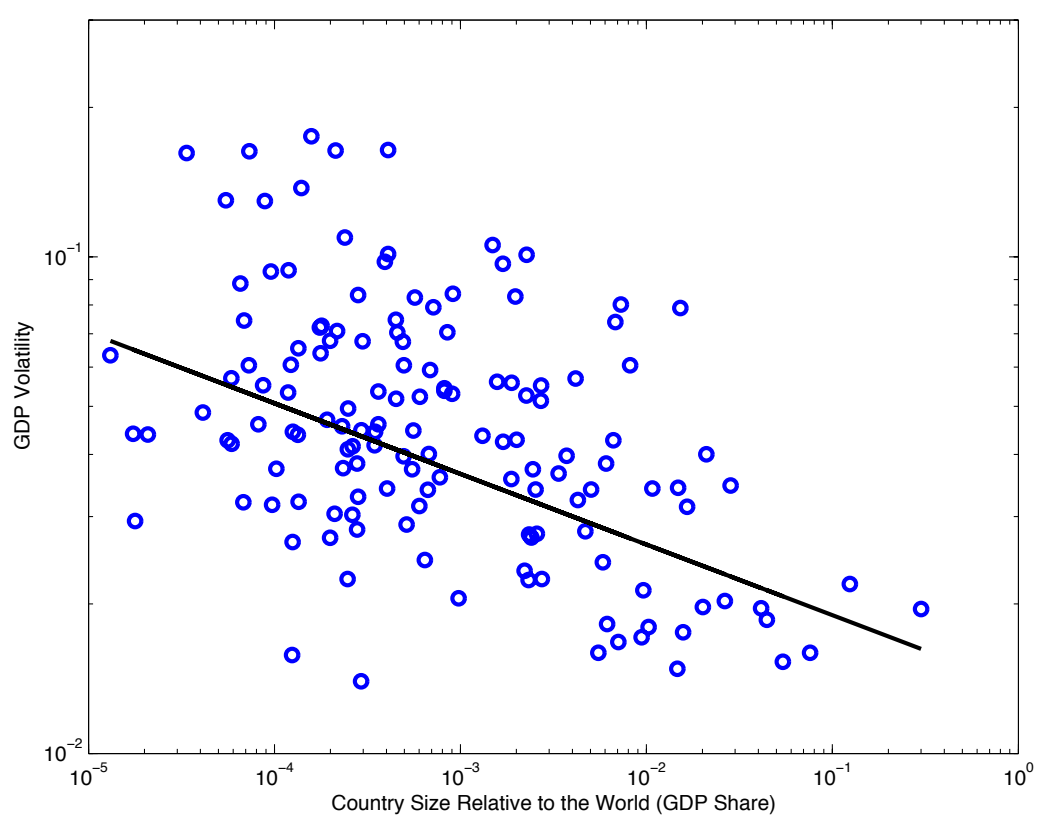

Notes: This figure reports the partial correlation plot of aggregate volatility, measured as the standard deviation of the annual growth rate of per capita GDP over 1970-2006, on the y-axis against country size on the x-axis, after netting out the impact of per capita income. Both axes are in log scale. Source: The World Bank (2007b). 
Figure 2. Korean Business Groups' Sales As a Share of GDP and Total Exports

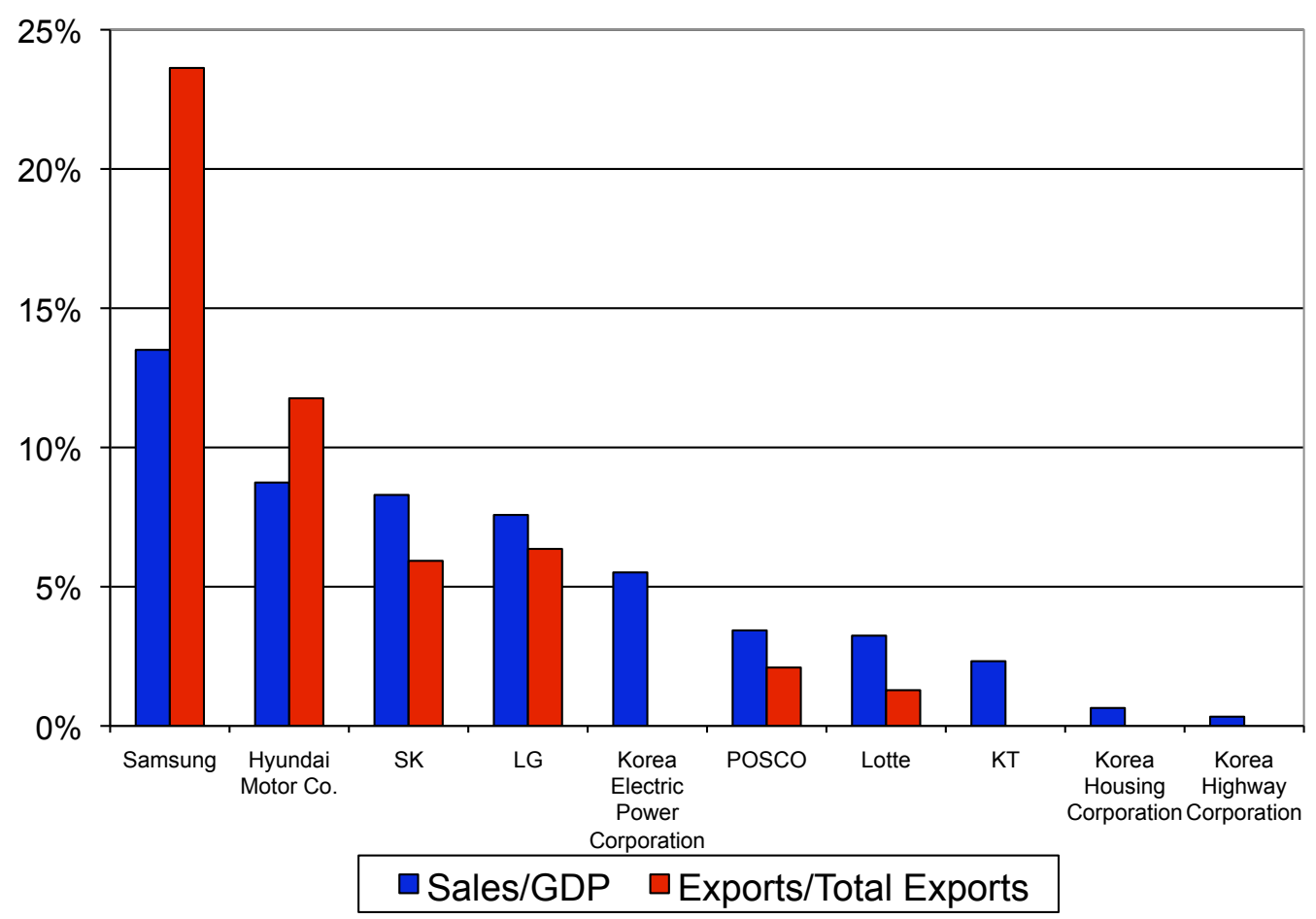

Notes: This figure reports the 2006 sales of the top 10 Korean business groups, as a share of Korean GDP (blue/dark bars) and total Korean exports (red/light bars). Source: Korean Development Institute. 
Figure 3. Country Size, Firm Sales Concentration, and Size of Large Firms

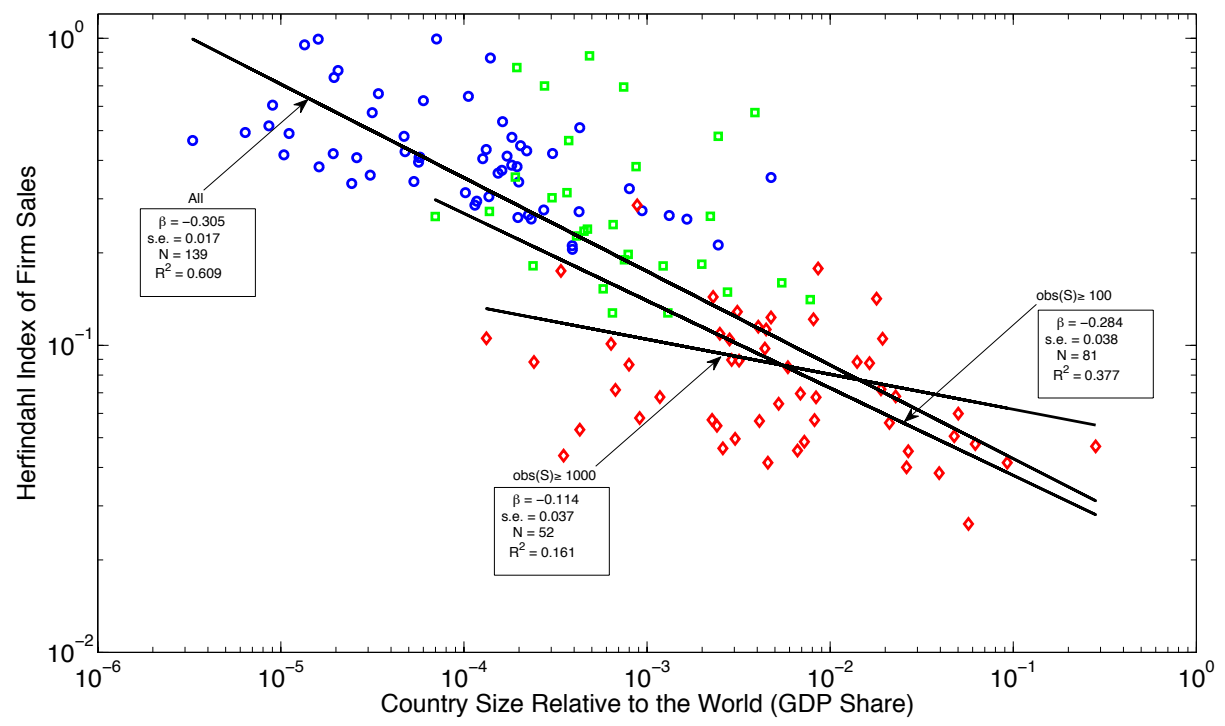

(a) Country Size and Firm Herfindahl Indices

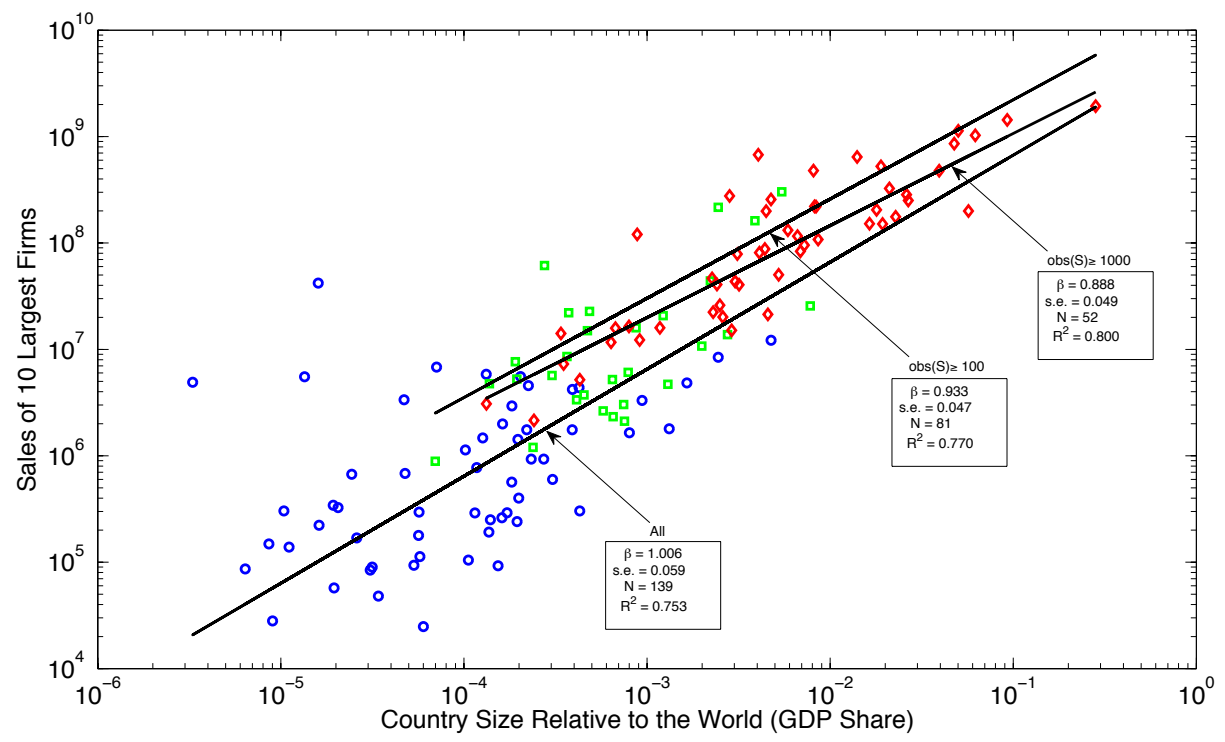

(b) Country Size and the Size of the 10 Largest Firms

Notes: These figures present the scatterplots of log country size and (a) the log Herfindahl index of firm sales; (b) the log size of the 10 largest firms, and (c) the log size of the largest firm, in all cases after netting out per capita GDP. The countries with more than 1000 firms with sales data are labeled with $\diamond$ 's; the countries with between 100 and 1000 firms with sales data are labeled with $\square$ 's, and the countries with less than 100 firms with sales data with o's. The regression lines through the samples of (i) all countries; (ii) countries with $\geq 100$ firms; and (iii) countries with $\geq 1000$ firms are plotted through the data. Both axes are in log scale. Sources: ORBIS and The World Bank (2007b). 
Figure 3. Country Size, Firm Sales Concentration, and Size of Large Firms (Cont'd)

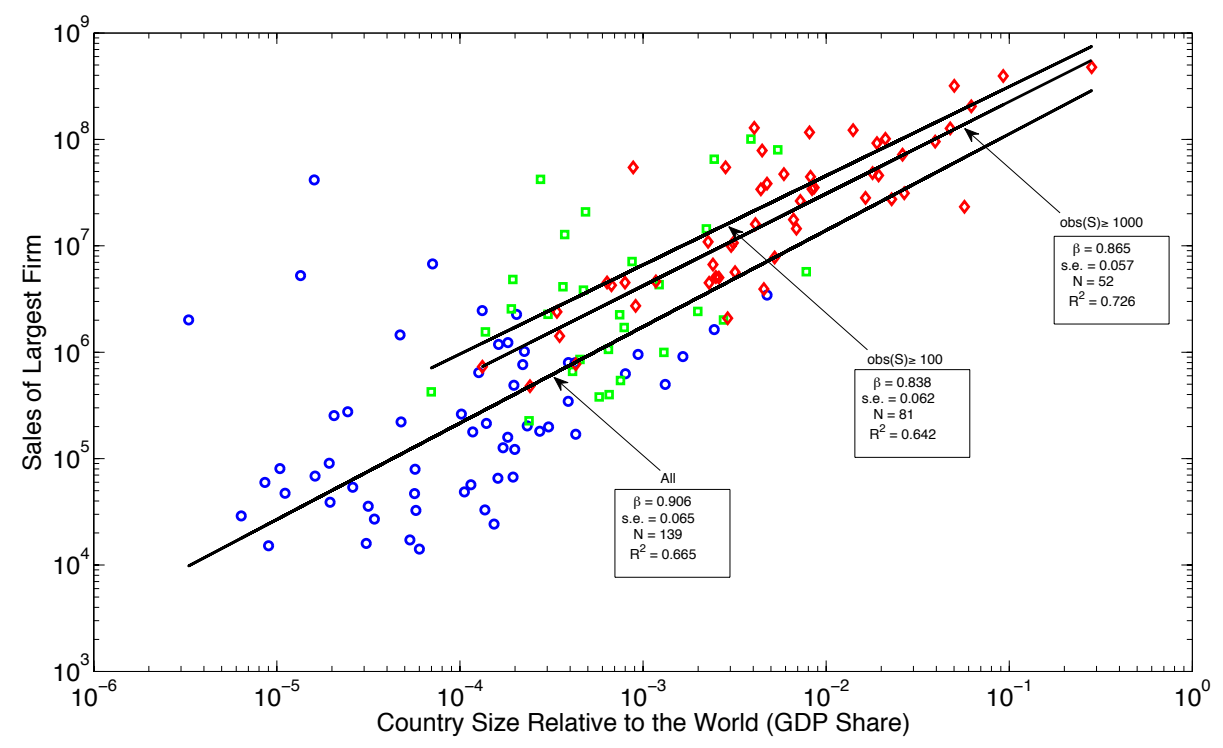

(c) Country Size and the Size of the Largest Firm

Notes: These figures present the scatterplots of log country size and (a) the log Herfindahl index of firm sales; (b) the log size of the 10 largest firms, and (c) the log size of the largest firm, in all cases after netting out per capita GDP. The countries with more than 1000 firms with sales data are labeled with $\diamond$ 's; the countries with between 100 and 1000 firms with sales data are labeled with $\square$ 's, and the countries with less than 100 firms with sales data with o's. The regression lines through the samples of (i) all countries; (ii) countries with $\geq 100$ firms; and (iii) countries with $\geq 1000$ firms are plotted through the data. Both axes are in log scale. Sources: ORBIS and The World Bank (2007b). 
Figure 4. The Timing of the Economy

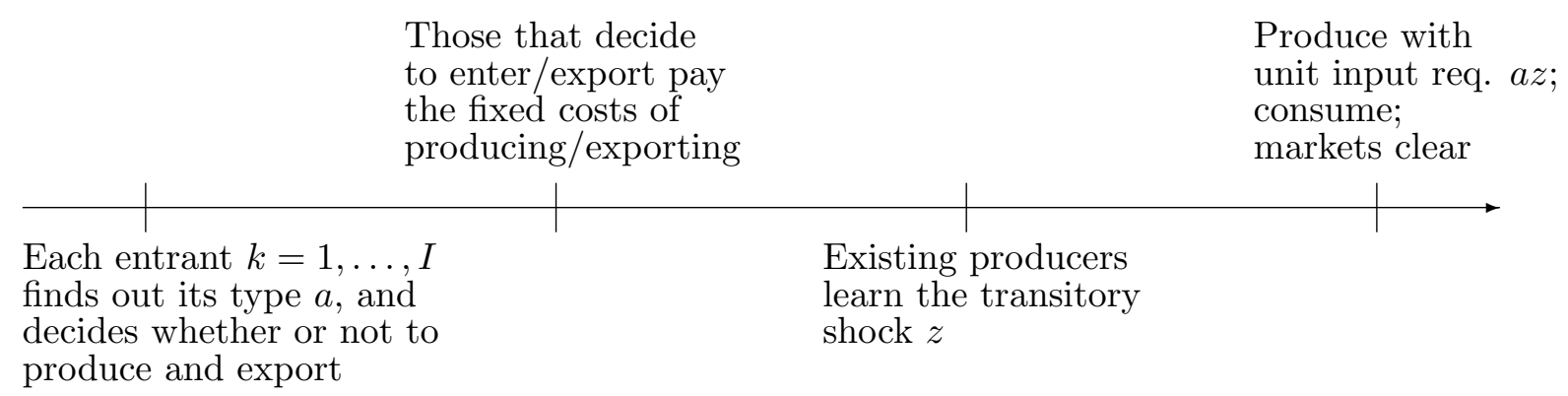

Figure 5. The Analytical Power Law in the Melitz-Pareto Model

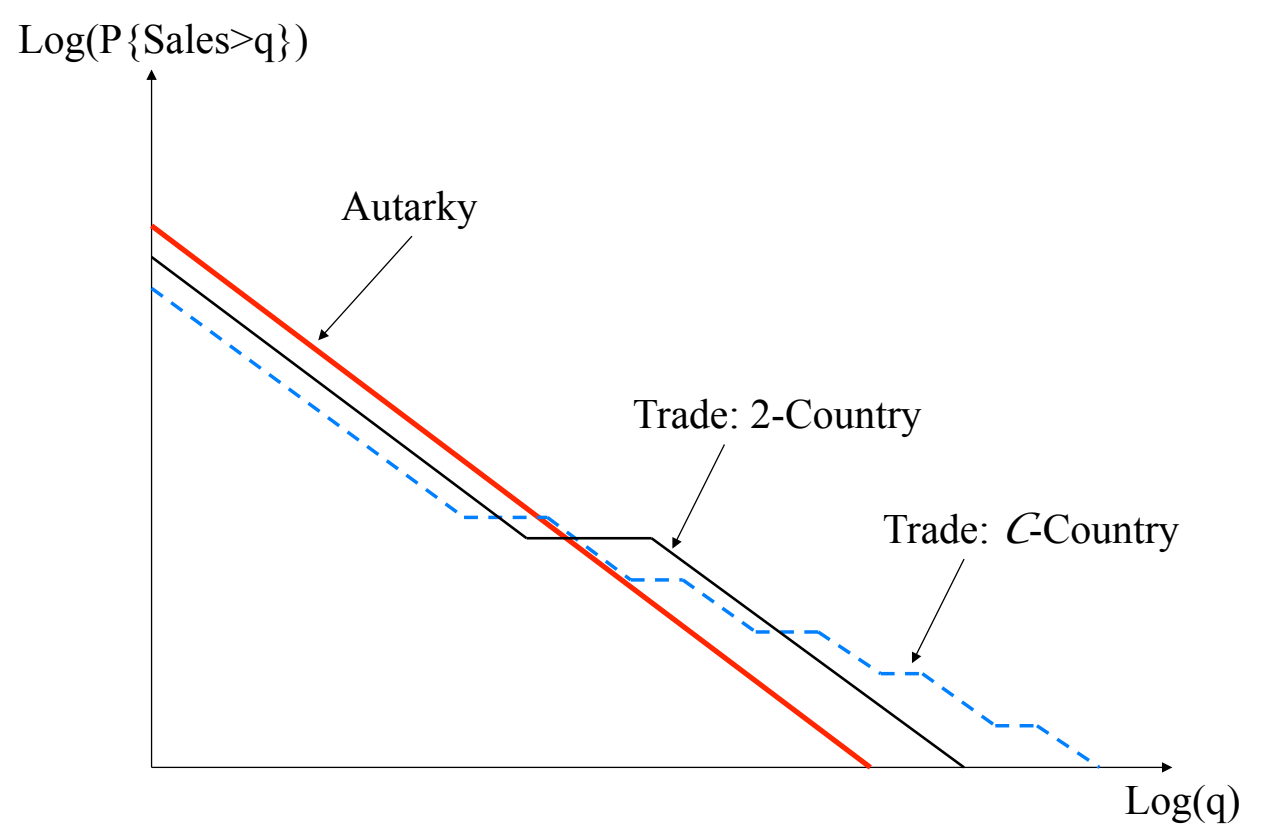

Notes: This figure depicts the distribution of firm size, measured by sales, and how it changes as it moves from Autarky to a 2-Country Trade equilibrium, and finally to a $\mathcal{C}$-Country Trade equilibrium. In the twocountry case, there is a single productivity cutoff, above which firms export abroad. Compared to autarky, there is a higher probability of finding larger firms above this cutoff. In the $\mathcal{C}$-country case, with multiple export markets there will be cutoffs for each market, with progressively more productive firms exporting to more and more markets and growing larger and larger relative to domestic GDP. 
Figure 6. Bilateral Trade Shares and Trade Openness: Data and Model Predictions

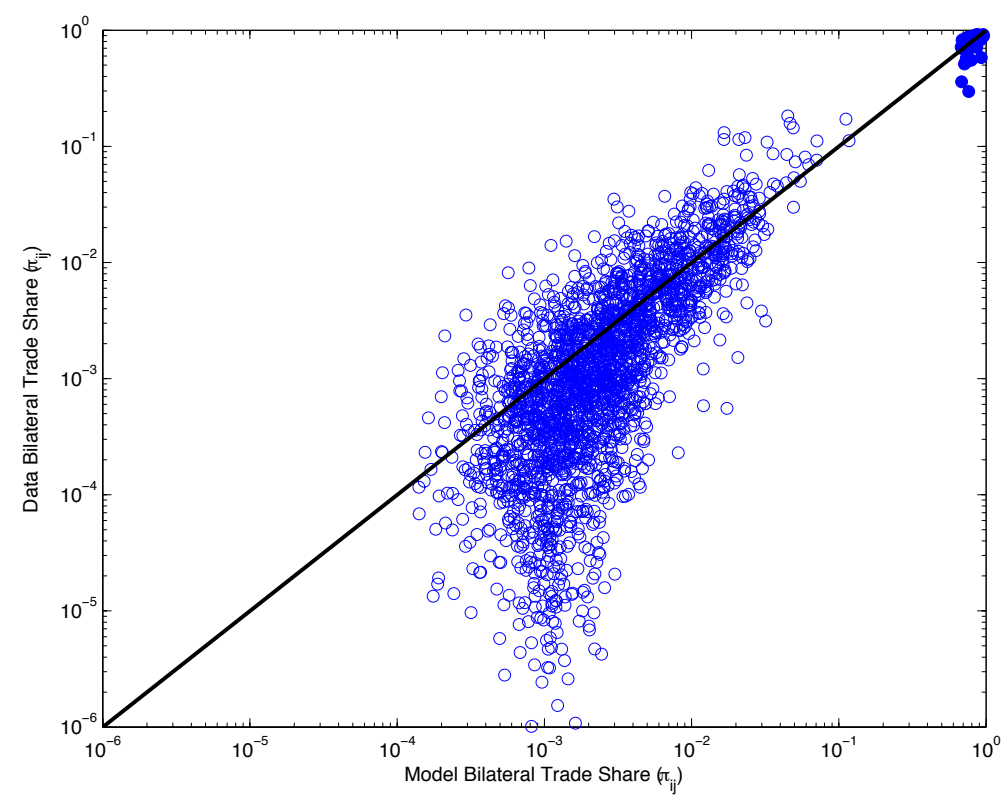

(a) Bilateral Trade Shares

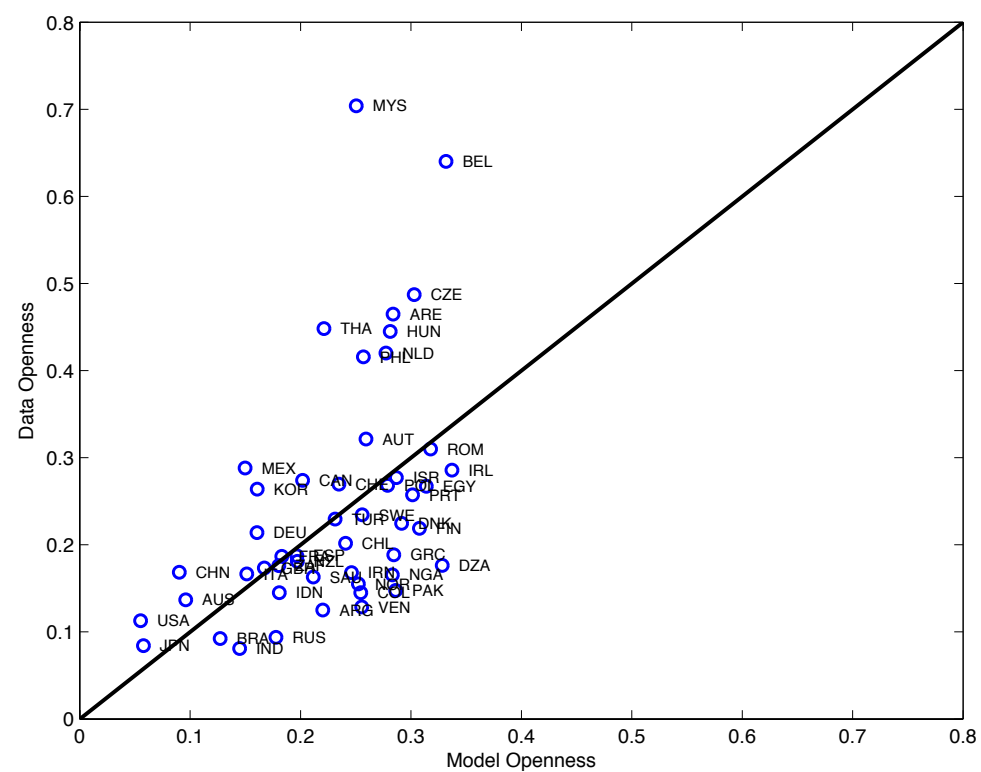

(b) Trade Openness

Notes: Figure (a) reports the scatterplot of domestic output $\left(\pi_{i i}\right)$ and bilateral trade $\left(\pi_{i j}\right)$, both as a share of country $i$ GDP. Solid dots represent observations of $\pi_{i i}$, while hollow dots represent bilateral trade observations $\left(\pi_{i j}\right)$. Both axes are in log scale. Figure (b) reports the scatterplot of total imports as a share of GDP. In both figures, the values implied by the model are on the horizontal axis; actual values are on the vertical axis, and the line through the data is the 45-degree line. Source: International Monetary Fund (2007). 
Figure 7. Volatility and Country Size: Data and Model Predictions

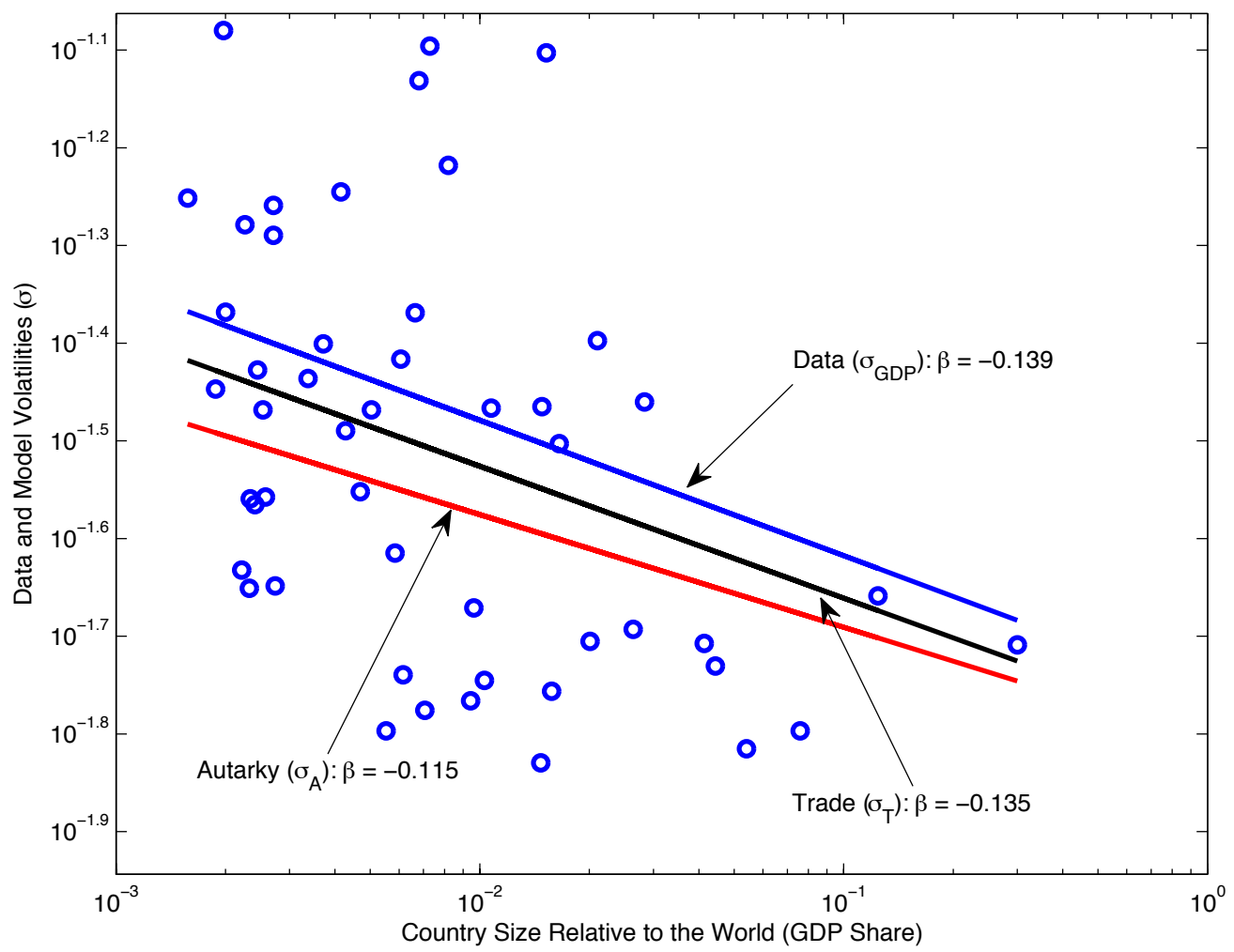

Notes: This figure plots the relationship between country size and aggregate volatility implied by the data (conditioning on per capita GDP), the model under trade, and the model in autarky. The dots represent actual observations of volatility. Note that the data points and regression line are shifted by a constant for ease of visual comparability with the model regressions lines. Source: The World Bank (2007b). 
Table A1. Aggregate Volatility and Country Size Regressions

\begin{tabular}{lcccccc}
\hline \hline & $(1)$ & $(2)$ & $(3)$ & $(4)$ & $(5)$ & $(6)$ \\
\hline Dep. Var: Log(GDP Volatility) & & & & & & \\
& & & & & & \\
$\log ($ Size $)$ & $-0.177^{* *}$ & $-0.139^{* *}$ & $-0.090+$ & $-0.209^{* *}$ & $-0.180^{* *}$ & $-0.142^{* *}$ \\
& $(0.038)$ & $(0.044)$ & $(0.045)$ & $(0.035)$ & $(0.027)$ & $(0.023)$ \\
$\log ($ GDP per capita) & & $-0.157^{*}$ & $-0.261^{* *}$ & -0.049 & -0.019 & 0.018 \\
& & $(0.069)$ & $(0.070)$ & $(0.057)$ & $(0.045)$ & $(0.037)$ \\
Constant & $-4.352^{* *}$ & $-2.696^{* *}$ & $-1.533+$ & $-4.010^{* *}$ & $-4.154^{* *}$ & $-4.291^{* *}$ \\
& $(0.190)$ & $(0.763)$ & $(0.773)$ & $(0.601)$ & $(0.473)$ & $(0.410)$ \\
\hline Observations & 49 & 49 & 30 & 75 & 100 & 143 \\
$R^{2}$ & 0.192 & 0.273 & 0.337 & 0.328 & 0.296 & 0.225 \\
\hline
\end{tabular}

Notes: The dependent variable is the log of the standard deviation of per capita GDP growth over the period 1970-2006. Size is a country's GDP as a share of world GDP; GDP per capita is PPP-adjusted per capita income. All right-hand side variables are averages over 1970-2006. Robust standard errors in parentheses; + significant at $10 \% ;{ }^{*}$ significant at $5 \% ; * *$ significant at $1 \%$. 
Table A2. U.S. Evidence on Relationship between Firm-Level Volatility and Exporter Status and Size

\begin{tabular}{|c|c|c|c|c|}
\hline & \multicolumn{4}{|c|}{ (A) Sample period: $1980-2007$} \\
\hline & \multicolumn{2}{|c|}{ Growth } & \multicolumn{2}{|c|}{ Granular } \\
\hline & $(1)$ & $(2)$ & $(1)$ & $(2)$ \\
\hline & All & Restricted & All & Restricted \\
\hline \multirow[t]{2}{*}{ Exporter } & -0.022 & -0.014 & -0.024 & -0.017 \\
\hline & $(0.021)$ & $(0.022)$ & $(0.021)$ & $(0.023)$ \\
\hline \multirow[t]{2}{*}{$\log ($ Sales $)$} & $-0.129 * *$ & $-0.135^{* *}$ & $-0.128^{* *}$ & $-0.133^{* *}$ \\
\hline & $(0.005)$ & $(0.005)$ & $(0.005)$ & $(0.004)$ \\
\hline Observations & 15,901 & 14,597 & 15,859 & 14,558 \\
\hline Number of SIC & 440 & 415 & 427 & 403 \\
\hline$R^{2}$ & 0.181 & 0.183 & 0.198 & 0.201 \\
\hline
\end{tabular}

(B) Sample period: 1980-1989

Growth

\begin{tabular}{|c|c|c|c|c|}
\hline & (1) & (2) & (1) & $(2)$ \\
\hline & All & Restricted & All & Restricted \\
\hline \multirow[t]{2}{*}{ Exporter } & -0.020 & -0.013 & -0.010 & -0.013 \\
\hline & $(0.021)$ & $(0.023)$ & $(0.020)$ & $(0.023)$ \\
\hline \multirow[t]{2}{*}{ Log(Sales) } & $-0.128^{* *}$ & $-0.133^{* *}$ & $-0.126^{* *}$ & $-0.133^{* *}$ \\
\hline & $(0.005)$ & $(0.006)$ & $(0.004)$ & $(0.006)$ \\
\hline Observations & 8,529 & 7,693 & 8,509 & 7,693 \\
\hline Number of SIC & 435 & 410 & 422 & 410 \\
\hline \multirow[t]{5}{*}{$R^{2}$} & 0.171 & 0.170 & 0.181 & 0.170 \\
\hline & \multicolumn{4}{|c|}{ (C) Sample period: $1990-2007$} \\
\hline & \multicolumn{2}{|c|}{ Growth } & \multicolumn{2}{|c|}{ Granular } \\
\hline & $(1)$ & $(2)$ & (1) & $(2)$ \\
\hline & All & Restricted & All & Restricted \\
\hline \multirow[t]{2}{*}{ Exporter } & -0.025 & -0.021 & -0.041 & -0.036 \\
\hline & $(0.029)$ & $(0.031)$ & $(0.029)$ & $(0.031)$ \\
\hline \multirow[t]{2}{*}{ Log(Sales) } & $-0.136^{* *}$ & $-0.140^{* *}$ & $-0.134^{* *}$ & $-0.140^{* *}$ \\
\hline & $(0.008)$ & $(0.008)$ & $(0.008)$ & $(0.007)$ \\
\hline Number of SIC & 409 & 386 & 398 & 375 \\
\hline Observations & 6,881 & 6,467 & 6,857 & 6,443 \\
\hline$R^{2}$ & 0.149 & 0.151 & 0.165 & 0.174 \\
\hline
\end{tabular}

Notes: This table presents the results from regressing a measure of firm-level sales volatility on measures of its export status ('Exporter') and size ('Sales'). Columns (1) and (2) ('Growth') take the natural logarithm of the standard deviation of firm real sales as the dependent variable. Columns (3) and (4) ('Granular') use a granular volatility measure, calculated as the standard deviation of the estimated residuals, $\hat{\varepsilon}_{i s t}$, from the following firm-level panel regression: $\Delta \log \left(\operatorname{Sales}_{i s t}\right)=\alpha_{i}+\alpha_{s t}+\varepsilon_{i s t}$, where $i$ is a firm, $s$ is a sector, and $t$ is a quarter, so that $\alpha_{i}$ is a firm-level effect, and $\alpha_{s t}$ is a sector $\times$ time effect. Standard deviations are calculated over the given sample period, while export status and measures of firm size are averaged over the period. Regressions include sector-level fixed effects at the 4-digit SIC. 'All' includes all firms, while 'Restricted' excludes firms in the commodity, energy, and public sectors. Data are taken from the Compustat Quarterly database of listed U.S. firms together with information on whether a firm is an exporter from the Compustat Segments database. Robust standard errors in parentheses; + significant at $10 \%$; significant at $5 \%$; ** significant at $1 \%$. 